\title{
Molecular features and gene expression signature of metastatic colorectal cancer (Review)
}

\author{
MARTINA POTURNAJOVA ${ }^{1}$, TATIANA FURIELOVA ${ }^{2}$, SONA BALINTOVA $^{2}$, \\ SILVIA SCHMIDTOVA $^{1,3}$, LUCIA KUCEROVA ${ }^{1}$ and MIROSLAVA MATUSKOVA ${ }^{1}$ \\ ${ }^{1}$ Department of Molecular Oncology, Cancer Research Institute, Biomedical Research Center of \\ Slovak Academy of Sciences, University Science Park for Biomedicine, 84505 Bratislava; \\ ${ }^{2}$ Department of Genetics, Faculty of Natural Sciences, Comenius University, 84215 Bratislava; \\ ${ }^{3}$ Translational Research Unit, Faculty of Medicine, Comenius University, 81499 Bratislava, Slovakia
}

Received April 5, 2020; Accepted December 4, 2020

DOI: $10.3892 /$ or.2021.7961

\begin{abstract}
Uncontrollable metastatic outgrowth process is the leading cause of mortality worldwide, even in the case of colorectal cancer. Colorectal cancer (CRC) accounts for approximately $10 \%$ of all annually diagnosed cancers and $50 \%$ of CRC patients will develop metastases in the course of disease. Most patients with metastatic CRC have incurable disease. Even if patients undergo resection of liver metastases,
\end{abstract}

Correspondence to: Dr Martina Poturnajova, Department of Molecular Oncology, Cancer Research Institute, Biomedical Research Center of Slovak Academy of Sciences, University Science Park for Biomedicine, Dubravska cesta 9, 84505 Bratislava, Slovakia E-mail:martina.poturnajova@savba.sk

Abbreviations: ADAM, A disintegrin and metalloproteinase; AKT1 (PKB), protein kinase $\mathrm{B}$; ALDH1A1, 3, aldehyde dehydrogenase 1 isoforms A1, A3; AMER1, APC membrane recruitment protein 1; AP4, murine transcription factor activator protein 4; APC, adenomatous polyposis coli; APOH, apolipoprotein $\mathrm{H}$; ATM, ATM serine/threonine kinase; BRAF, serine/threonine-protein kinase; $\mathrm{CAF}$,carcinoma-associated fibroblast; cAMP, cyclic adenosine monophosphate; CD133, transmembrane glycoprotein prominin-1; CD26, dipeptidyl peptidase-4; CD44, homing cell adhesion molecule; CDCP1, CUB domain-containing protein 1; CDX2, homeobox transcription factor 2; CIN, chromosomal instability; CK1 $\alpha$, casein kinase $1 \alpha$; CMS, classification of molecular subtypes; $\mathrm{CRC}$, colorectal cancer; CSC, cancer stem cell; CTC, circulating tumour cell; CXCL14, C-X-C motif chemokine ligand 14; CXCR4, C-X-C chemokine receptor type 4; ECM, extracellular matrix; EGFR, epidermal growth factor receptor; EMT, epithelial-mesenchymal transition; EpCAM, epithelial cell adhesion molecule; ErbB2, (NEU, HER2) receptor tyrosine kinase; ErbB3, (HER3) receptor tyrosine kinase; ERK, extracellular signal-regulated kinase; ERK1, 2, extracellular signal-regulated kinases 1, 2; F5, factor five, protein of the coagulation system; FOXC2, forkhead box protein C2; FRA-1, Fos-related antigen 1; FXR1-Fragile X mental retardation syndrome-related protein 1; GATA, transcription factor; GDP/GTP, guanosine diphosphate/guanosine triphosphate; GLUT1, 3, Glucose transporter 1, 3; GNAS, heterotrimeric g-protein $\alpha$ subunit Gs- $\alpha$; GPC6, glypican-6; GRB2, growth factor receptor-bound protein 2; GSK3 $\beta$, glycogen synthase kinase $3 \beta$; HGF, hepatocyte growth factor; HIF-1 $\alpha$, hypoxia-inducible factor-1 $\alpha$; HMGA1, high-mobility group gene; $\mathrm{ITH}$, intratumoural heterogeneity; JNK, c-Jun N-terminal kinase; Klf4, kruppel-like factor 4; LCRC, left-sided colorectal carcinoma; LEF 1, lymphoid enhancer-binding factor 1; LGR5, leucine-rich repeat-containing
G-protein coupled receptor 5; LRP, low-density lipoprotein-related protein; MACC1, metastasis-associated in colon cancer-1; MAPK, mitogen-activated protein kinase; mCRC, metastatic CRC; MECOM, MDS1 and EVI1 complex locus protein EVI1; MEIS2,Homeobox 2; MEK, mitogen-activated protein kinase kinase; MEK1, 2, mitogen-activated protein kinases 1, 2; cMET (HGFR), hepatocyte growth factor receptor; MLH1, MutL homolog 1; MMP, matrix metalloproteinase; MSH2, 6, MutS homolog 2, 6; MSI, microsatellite instability; MSS, microsatellite stability; mTOR, mammalian target of rapamycin, mTORC1, 2, mammalian target of rapamycin complex 1, 2; MUC4, mucin 4 glycoprotein; NANOG, homeobox protein, transcriptional factor; $\mathrm{NF \kappa B}$, nuclear factor $\kappa$-light-chain-enhancer of activated B cells; NGS, next-generation sequencing; NK, natural killer; Notch1, Notch homolog 1, transmembrane receptor; NRG, neuroregulin; OCT4, octamer-binding transcription factor 4PKB-Protein kinase B; PD-1, programmed cell death protein 1; PDCD4, programmed cell death protein 4; PDK1, phosphoinositide-dependent kinase-1; PD-L1, programmed death-ligand 1; PGC-1 $\beta$, peroxisome proliferator-activated receptor $\gamma$ coactivator $1-\beta ;$ PI3K, phosphatidylinositol 3-kinase; PIK3CA, phosphatidylinositol-4,5-bisphosphate 3-kinase, catalytic subunit $\alpha$; PIP2, phosphatidylinositol-4,5-bisphosphate; PIP3, phosphatidylinositol-3,4,5-triphosphate; PKA, protein kinase A; PKB, protein kinase B; PMS1, 2, PMS1 protein homolog 1,2; PP2A, protein phosphatase 2A; PROX1, Prospero homeobox protein 1; PRRX1, paired related homeobox 1; PTEN, phosphatase and tensin homolog; PTPRT, receptor-type tyrosine-protein phosphatase $\mathrm{T}$; $\mathrm{RACl}$, Ras-related $\mathrm{C} 3$ botulinum toxin substrate 1; RCRC, right-sided colorectal carcinoma; RhoA, member of family of GTPases; RICTOR, rapamycin-insensitive companion of mammalian target of rapamycin; S100A4, S100 calcium-bindingprotein A4;SAM,S-adenosylmethionine;SIX1,Homeobox protein; sLeA, sialyl Lewis A; sLeX, sialyl Lewis X; SMAD2, 4, Mothers against decapentaplegic homolog 2, 4; SNAI1, (Snail) zinc finger protein 1; SNAI2, (Slug) zinc finger protein 2; SOS, son of sevenless; SOX2, SRY (sex determining region Y)-box 2; SRC, Proto-oncogene tyrosine-protein kinase; STAT3, 5, Signal transducer and activator of transcription 3, 5; SW620, colorectal carcinoma cell line; TAM, tumour-associated macrophage; TCA, citric acid (Krebs) cycle; TCF4 (TCF7L2), transcription factor 7-like 2 ; TGF- $\beta$, transforming growth factor- $\beta$; TIL, tumour-infiltrating lymphocytes; TME, tumour microenvironment; TP53, cellular tumour antigen p53; TWIST1,2, TWIST-related protein 1, 2; VEGFR-1, vascular endothelial growth factor receptor 1; WNT5A, WNT family member 5A; YAP, Yes-associated protein; ZEB1, 2, Zinc finger E-box-binding homeobox 1,2

Key words: metastasis, metastatic colorectal cancer, molecular determinants of metastatic competence 
the 5-year survival rate ranges from 25 to $58 \%$. Next-generation sequencing of tumour specimens from large colorectal cancer patient cohorts has led to major advances in elucidating the genomic landscape of these tumours and paired metastases. The expression profiles of primary CRC and their metastatic lesions at both the gene and pathway levels were compared and led to the selection of early driver genes responsible for carcinogenesis and metastasis-specific genes that increased the metastatic process. The genetic, transcriptional and epigenetic alteration encoded by these genes and their combination influence many pivotal signalling pathways, enabling the dissemination and outgrowth in distant organs. Therapeutic regimens affecting several different active pathways may have important implications for therapeutic efficacy.

\section{Contents}

\section{Introduction}

2. Biology of metastatic colorectal cancer

3. Pattern of colorectal cancer metastasis

4. Functional traits of metastatic cells

5. CMS classification of primary tumours do not fully correspond to their metastasis

6. Identification of metastatic CRC markers

7. Gene signature of metastatic CRC cells

8. Signalling pathways involved in metastatic CRC

9. Metastasis connected to the localisation of CRC

10. Modulation of microenvironment

11. Metabolic reprogramming in metastatic CRC

12. Effect of miRNAs on the metastatic process of CRC

13. Epigenetic changes in metastatic CRC

14. Conclusion

\section{Introduction}

From a genomic standpoint, colorectal cancer is not a single disease, but a heterogeneous group of malignancies arising within the colon and rectum. Colorectal cancer accounts for approximately $10 \%$ of all annually diagnosed cancers and cancer-related deaths worldwide. Currently, it is the world's fourth deadliest cancer with almost 900,000 deaths annually $(1,2)$. Metastasis to either liver, lung, brain or peritoneum is present in about $90 \%$ of patients with stage IV disease. Twenty percent of CRC patients have metastases at the time of diagnosis. About $40 \%$ of patients with stage II-III succumb to recurrence in the next 5 years after surgical treatment (3). Liver metastases are often detected only in advanced disease and even when resection is combined with modern adjuvant systemic regimens, it is curative in only $20 \%$ of patients, with $70 \%$ developing recurrence. Owing to difficulties in the detection and treatment of the metastatic spread of CRC, the research is based on identifying high-risk patient cohorts and new biomarkers based on the differences between metastatic vs. non-metastatic cells (4).

Colon cancer progresses through a well-defined series of transformations from normal colonic epithelial cells into precursor adenoma lesions which eventually evolve to increasingly more invasive and malignant stages. Generally, the defining hallmark of metastasis is development of any secondary mass that is no longer directly connected to the originating tumour. Metastases are distinct and unique subsets of cells that emigrated from the primary tumour and are molecularly, genetically, and biochemically distinct from the cells remaining at the site of tumour origin (5).

Metastatic cells are able to successfully dissociate, disseminate, and colonize secondary sites, so they acquire properties in addition to those necessary to become neoplastic: Motility and invasion, ability to modulate the secondary site or local microenvironments, plasticity, and ability to colonize secondary tissues $(5,6)$. The generation of the tumour in a foreign organ is tightly bound to the acquisition of a stem-like phenotype by cancer cells. Recent findings suggest that cancer stem cells (CSCs) are a phenotypically and functionally heterogeneous population, which is dynamic and is able to adapt as a result of various extrinsic and intrinsic cellular factors (7). Metastatic stem cells use multiple phenotypes and behaviours and critically depend on their interaction with the microenvironment to migrate, survive in the circulation and thrive in a foreign organ (8).

A large study of CRC patients investigating the molecular differences between primary tumours, lymph node metastases and distant metastases using next-generation sequencing (NGS) and immunohistochemistry showed that lymphatic and distant metastases harbour different mutation profiles compared to their primary tumour and between each other (9). The transcriptomes of primary CRC and their metastatic lesions at both the gene and pathway levels were compared and showed differences between them (10). Principles and differences with respect to CRC organotropism, epithelial-mesenchymal transition, angiogenesis and inflammation were also published (11). However, a complex summary of the traits of metastatic colorectal cells through the lens of molecular biology is missing.

This review therefore summarises biological properties of metastatic colorectal cells, their genetic and molecular determinants of metastatic competence and active molecular pathways. A deeper understanding of molecular signatures of metastatic cells can lead to finding new therapeutic targets and drug regimens to cure metastatic dissemination.

\section{Biology of metastatic colorectal cancer}

Metastatic cells have the ability, the metastatic competence, to fine-tune malignant properties of primary tumour cancer cells by building upon an already tumourigenic program, enhancing their own stem-like features and becoming predominant during disease progression and metastatic dissemination.

According to the traditional model of progressive acquisition of mutations during colon cancerogenesis, the metastatic capacity/competence is acquired later in time during the multi-step tumour progression process after accumulation of genetic alterations. $K-R A S, B-R A F, A P C$ and $P 53$ mutations in case of CIN and mutations in the mismatch repair genes in case of MSI result in the gradual transition of an adenoma into carcinoma (12). Metastatic ability is thought to be acquired in later stages of carcinogenesis. A limited number of cells acquire the ability to move from the primary tumour into the bloodstream or lymphatic system, to migrate to a distant location in the body and to grow into tumours in the new location (12).

On the other hand, even in 2003, a study from Ramaswamy et al suggested a novel idea about rare cells with 


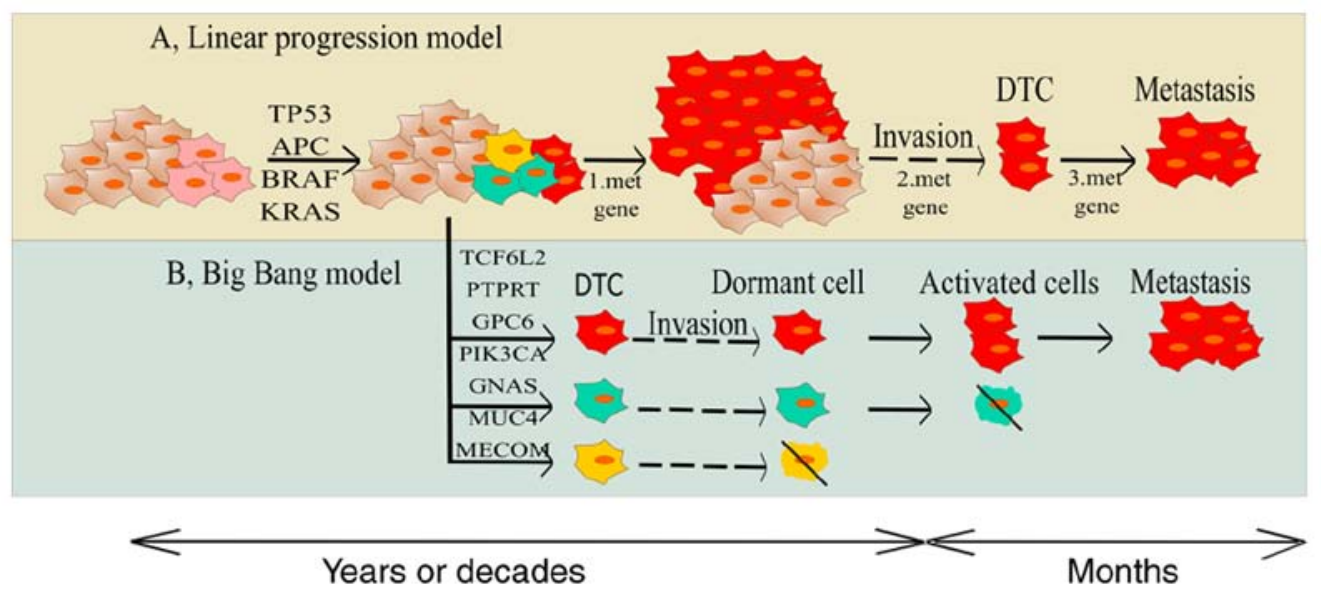

Figure 1. Two models regarding gaining metastatic competence. (A) Tranditional model is the concept of transition of initiated cell to more aggressive state and gaining of metastatic ability due to the accumulation of genetic and epigenetic changes. (B) The second model explains that there are some clones in tumour bulk with metastatic potential already present in early stages of carcinogenesis and their individual gene signature is predictive for the invasiveness and distant recurrence. APC, adenomatous polyposis coli; CIN, chromosome instability; DTC, dormant tumour cells; MSI, microsatellite instability; SMAD4, mothers against decapentaplegic homolog 4; PIK3CA, phosphatidylinositol-4,5-bisphosphate 3-kinase catalytic subunit alpha; TCF7L2, transcription factor 7-like 2; AMER1, APC membrane recruitment protein 1; PTPRT, Receptor-type tyrosine-protein phosphatase T; GNAS, heterotrimeric G-protein alpha subunit $\mathrm{G}_{\mathrm{s}}-\alpha$; FXR1, fragile X mental retardation syndrome-related protein 1; MUC4, Mucin 4; GPC6, Glypican-6; MECOM, MDS1 and EVI1 complex locus protein EVI1.

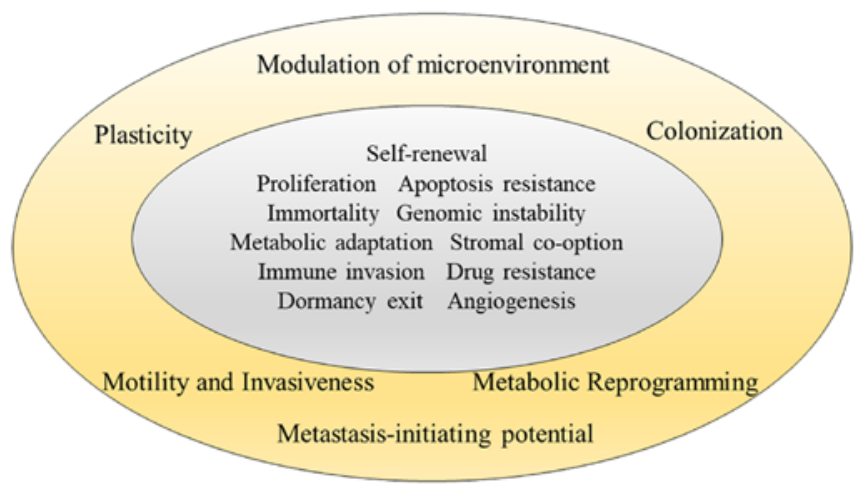

Figure 2. The hallmarks of metastatic cells. Metastatic cells keep all essential 'hallmarks of cancer' (the core of the image) and expand them by acquiring certain traits (the periphery of the picture): Plasticity, motility and invasion, capability to modulate the local microenvironments and the ability to colonize secondary tissues. Prior to becoming metastatic, the cells lose the capacity to fully differentiate; they are not inhibited by cell-cell contact; they are not anchorage-dependent; and are genetically unstable.

an ability to metastasize within a primary tumour. Those authors showed that the metastatic potential of human tumours is encoded in the bulk of a primary tumour and the gene expression signatures of primary tumours are predictive of distant recurrence (13) (Fig. 1). Close genetic relationships between primary tumours and metastases in a variety of cancer types indicate that, at least in certain cases, the cells forming a metastatic colony derive from a dominant clonal subpopulation of the primary tumour. These populations manage to complete all of the steps required both for primary tumour formation and the subsequent multi-step invasion of metastasis cascade (14). The completion of this cascade depends not only on genetic changes but especially on specifically epigenetically organized programs that complement the previously acquired genetic mutations (6).

The 'Big Bang' theory of tumour evolution says that after transformation some cancer cells grow as a single expansion giving rise to effective subclones constituting intratumoural heterogeneity (ITH) (15). Genomic profiling of 349 individual samples from 15 colorectal tumours showed an absence of selective steps, uniformly high ITH and subclone mixing in distant regions. The most detectable ITH originates from early private alterations and not from later clonal expansions (16). Recently, large NGS studies of paired colorectal cancer and their metastases were performed showing that the primary tumours' vs. paired metastases' genomic divergence is low and their invasive and metastatic potential were acquired early, even during the time the tumour could not be diagnosed (17). An important finding is that the vast majority $(90 \%)$ of primary tumours exhibits subclonal selection consistent with the metastatic clone gaining a selective growth advantage. On the other hand, subclonal selection was detected only in $33 \%$ of patients with early-stage CRC (17).

\section{Pattern of colorectal cancer metastasis}

Colorectal cancer shows sequential organ-specific colonization, with the first site of metastasis being usually the liver and secondarily the lung. Focusing on these most frequent metastatic sites, $70 \%$ of colorectal cancer metastasizes to the liver, and $47.5 \%$ of the patients presented with metastases confined to the lungs, distant lymph nodes (16\%), and peritoneum (15\%) (18). When it comes to metastases arising from the colon and proximal parts of the rectum, the portal system guides the blood flow directly to the liver (Fig. 2). In hematogenous spread platelets and neutrophils help CTC by protecting them from elimination by NK cells. The entry of colorectal carcinoma cells into the hepatic microvasculature can initiate a pro-inflammatory cascade that results in Kupffer as well as stellate cells being triggered to secrete chemokines that upregulate vascular adhesion receptors, thereby enabling the adhesion of CTC in the microvasculature of the liver (19). Neutrophils support metastatic spread by forming an extracellular trap for CTC in the bloodstream helping them adhere to 


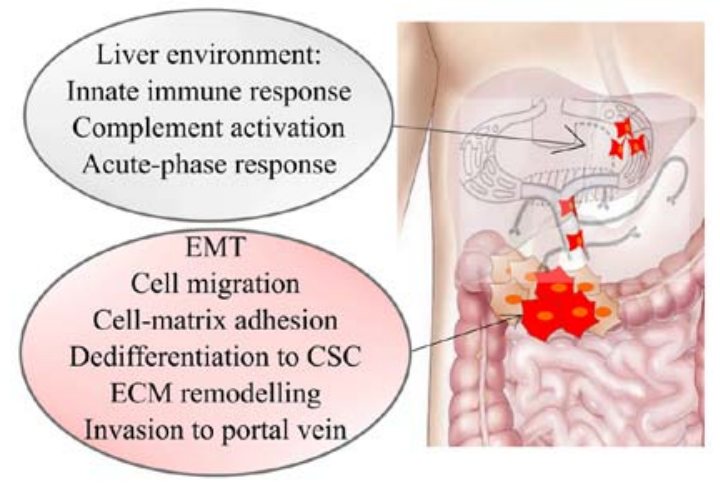

Figure 3. Metastatic spreading to the liver. Disseminating cells are subjected to EMT and dedifferentiation into cells with stem-like properties so as to gain the migratory ability. After ECM remodellation, they extravasated to vascular system and invaded the liver through the portal vein. The primary tumour itself actively supports preparation of the premetastatic niche by the activation of inflammatory and immune cells involving CAFs, neutrophils, macrophages and TAMs subtype 1. CAF, carcinoma-associated fibroblasts; TAM, tumour-associated macrophage; ECM, extracellular matrix.

endothelial cells and extravasate. The blood group antigens sLea and sLex may play an important role in the attachment (11). The primary tumour itself can actively support preparing of premetastatic niche by recruiting VEGFR-1 expressing haematopoietic progenitor cells. The pro-tumour microenvironment is composed of inflammatory and immune cells involving cancer-associated fibroblasts (CAFs), neutrophils and macrophages and environmental conditions such as hypoxia, soluble factors, signalling molecules, and ECM components. At the early stages, the proinflammatory TAMs subtype 1 are active and work to eliminate malignant cells. At later stages, macrophages switch to immunosuppressive TAMs subtype 2 creating the microenvironment permissive for tumour growth by secretion of ECM-degrading components (MMP1, 7, 9, 12) (11). The metastatic cascade ends with the invasion of colorectal cancer cells, as well as the adaptation and colonization of the hepatic parenchyma (11).

Lung metastases usually appeared together with liver metastases (73\% in colon cancer/60\% in rectal cancer) $(20,21)$. CRC cells disseminate through portal circulation to the liver, and from there to the lungs. Metastatic cells flow to the lungs directly by lymphatic system or from the distal rectum via systemic circulation through the hemorrhoidal veins. Metastases of bones and the nervous system in CRC patients occur more frequently in the patients with lung metastases, but are sporadic in patients with liver metastases (20). This indicated that the lungs are an important waypoint towards further metastatic dissemination (20). A study on the onset of growth of lung metastases revealed that some CRC patients with isolated synchronous liver metastasis already have lung metastases even when the metastatic sites are considered to be limited to the liver (22). Compared to other distal metastases, lung metastases grow slowly and have better overall survival (21).

Expression analysis of CRC metastasis revealed 22 specific genes related to liver metastasis and they were strongly associated with: i) Cell migration, adhesion, proliferation (cell adhesion/focal adhesion/chemokine signalling pathway/PI3K-AKT signalling pathway/APOH/ F5/CXCL14); and ii) immune response (innate immune response/complement activation/acute-phase response/SERPIN A1/CXCL14). CXCL14 may be a favourable prediction factor that is involved in liver metastasis of colon carcinoma (23). Signalling network analyses have indicated that the PI3K-AKT pathway is highly activated in liver metastases from colorectal cancer compared with matched primary tumours.

Testing of gene signature in the metastatic process of CRC lung metastasis revealed $A P C, T P 53$ and $K R A S$ being the most commonly mutated genes. Mutations in EGFR, GNAQ, KIT, $M E T$ and $P T P N 11$ genes were associated with an early pulmonary recurrence. The two strongest affected pathways were the RAS signalling pathway (EGFR, KIT, MET and PTPN11) and the RAP1 signalling pathway (EGFR, GNAQ, KIT and MET) (24).

CRC metastasizes within the abdominal cavity too, resulting in non-hematogenous metastases in ovaries. All parts of the gastrointestinal system share a mutual lymphatic drain, flowing to the left subclavian vein. Moreover, metastases may spread through the peritoneal fluid within the peritoneal cavity (25).

\section{Functional traits of metastatic cells}

Metastasis formation is a multi-step process involving invasion of primary tumour cells through the basement membrane and intravasation into nearby lymphatics or blood vessels. These tumour cells must then survive transport to distant organ sites (typically liver in CRC) where they extravasate and colonize the secondary organ site to establish micro-metastases, which proliferate to expand to macrometastases (26).

Any hallmarks of metastasis are superimposed upon the hallmarks of cancer itself published by Hanahan and Weinberg in 2000 and $2011(27,28)$. The traits of metastatic cells contain motility and invasion, ability to modulate the secondary site or local microenvironments, plasticity, and ability to colonize secondary tissues $(5,6)$ (Fig. 3).

Motility and invasion. To manifest their properties and live without connection to a primary tumour, the cells must possess the ability to move and penetrate through a basement membrane. Cellular movement requires coordinated cell-cell and cell-matrix adhesion, matrix degradation, and cytoskeletal activity. During motility and invasion, the cells organize adhesive, proteolytic, and motility components into specialized structures: Invadopodia (5).

One of the first steps in invasion in CRC is tumour budding (TB), which represents an infiltrating growth pattern at the invasive front. It promotes progression and dissemination of tumour cells by penetrating the vascular and lymphatic vessels. The balance between pro-tumour (budding) and anti-tumour (immune response or certain inflammatory cell types) factors at the invasive front of colorectal cancer may be decisive in determining tumour progression in CRC (29).

The invasive front in CRC tumours and interactions within it represent a critical interface encompassing a dynamic process of de-differentiation of colorectal carcinoma cells. Histopathological analyses of invasive cells suggest their internal complexity, with invading cells at the leading edge paving the way for subsequent cells to which they remain attached via cell-cell junctions (30). The leading cells at the invasive fronts exhibit certain mesenchymal traits during 
collective migration (31-33). In comparison to epithelial CRC cells, leading cells in the invasive front possess increased motility, invasiveness and the ability to degrade components of the extracellular matrix. Such invading leaders release proteases that degrade the extracellular matrix that would otherwise impede the forward progress of the cohort as a whole. Moreover, such leader cells may also possess the motility to enable the forward motion of the cohort as a whole (6).

Dedifferentiation of originally epithelial colorectal cancer cells to those with invasive potential and tumour-initiating capability is triggered by induction of epithelial-mesenchymal transition (EMT) programs (34-36). WNT signalling has a pivotal role in colon cancer initiation and consequent downstream EMT activation and also underlies the onset of migrating CSCs at the invasive front of the primary lesion which locally invade the tumour microenvironment and eventually form distant metastases (34). The dedifferentiation process may be an alternative mechanism in acquisition of CSC-like properties in human colorectal cancer cells. External stimulation with TGF- $\beta$ and the induction of TWIST1 converted the epithelial CRC into undifferentiated CSCs, leading to a significant increment of stem cell properties in human colorectal cancer (37).

EMT is characterised by a switch of production of E-cadherin (epithelial) to $\mathrm{N}$-cadherin. E-cadherin reduction is regulated by two groups of transcription factors: i) Direct repressors of E-cadherin including SNAI1 and 2, ZEB1, ZEB2, E12/E47, Brachyury, and AP4; ii) indirect repressors: Twist1,2, FOXC2, TCF4, SOX2, OCT4, NANOG, PROX1, SIX1, PRRX1, HMGA1, and FRA-1 that regulate the transcription of E-cadherin at different levels including activation of direct repressors $(11,38-47)$. With respect to the clinical significance in CRC, the repressors AP4, SOX2, and OCT4 have been associated with liver metastasis $(11,40,41)$. In addition, $85 \%$ of CRC patients show moderate to strong expression of the repressor Twist1 which is associated with nodal invasion and poor outcome. Upregulation of SNAI2 significantly correlates with strong Vimentin expression, and both SNAI2 and Vimentin expression is associated with lymph node metastasis and poor prognosis $(11,48)$.

In particular, RAS signalling has been reported to play a crucial role in EMT inducing a decrease of E-cadherin expression and an increase of Vimentin expression initiation $(49,50)$. $K R A S$ mutation alone is not able to modify the epithelial morphology of CRC cells but requires cooperation with TGF- $\beta$ growth factor to accomplish the cell transformation (51).

Recent studies revealed new potential molecules connected to CRC invasion. Wan et al revealed that MEIS2 serves a role as a promoter of metastasis in CRC. In vitro and in vivo experiments revealed that knockdown of MEIS2 significantly suppressed CRC migration, invasion and EMT (52). Considerable evidence indicates that S100A4 expression by cancer cells alters their adhesive properties, possibly by remodelling the ECM and promoting the redeployment of adhesion-mediating molecules. Additionally, the induction of S100A4 may be linked to the downregulation of E-cadherin and cytoskeletal dysregulation (53).

Extracellular matrices are remodelled by proteolytic enzymes that contribute to matrix degradation and facilitate tumour cell invasion, e.g., serine proteinases (plasmin, plasminogen activator, seprase, hepsin), cysteine proteinases (cathepsins B and K), aspartyl proteinases (cathepsins $\mathrm{D}$ and $\mathrm{E}$ ), and metal-dependent proteinases of the matrix metalloproteinase and a disintegrin and ADAM families (5).

Plasticity. Plasticity is the fundamental trait of metastatic cells (54) due to: i) The dynamics of epithelial-to-mesenchymal transition and the reverse process, ii) the redundancy of mechanisms to accomplish all steps in metastatic cascade (55), and iii) cell dedifferentiation and gaining of stemness potential early in the metastatic process compared to the dormancy exit and resumption of proliferation during metastasis formation in distant organs $(54,56,57)$. Chromatin remodelling complexes such as Polycomb and NuRD (Nucleosome Remodeling Deacetylase) regulate the transcription of EMT-related transcription factors $(58,59)$. Migrating cancer cells display intermediate phenotypes featuring both epithelial and mesenchymal (E/M) characteristics. These hybrid E/M cancer cells have been the focus of much attention as they are likely to be metastable and as such very efficient in causing metastasis, while cells with fixed epithelial or mesenchymal states lose their plasticity and associated stem cell capabilities (60). A study by Liu et al reported that mesenchymal-like CSCs exhibited high invasiveness and were quiescent, whereas epithelial-like CSCs were highly proliferative and less invasive (61). During colonization of distant organs, disseminated cells have to undergo MET to gain back their proliferative potential. The ability of cancer cells to revert back from EMT-induced phenotypes is critical for metastasis formation in distant organs and full mesenchymal transformation may result in the irreversible loss of MET capacity $(62,63)$.

Another form of plasticity is the fact that metastatic cells evolve more mechanisms on how to accomplish steps of the metastatic process. This redundancy provides a clear competitive advantage to cells and the loss of the ability to adapt (i.e., terminal differentiation) can block the ability to metastasize (55).

Colonization. Colonization is dependent on a combination of tumour cell- and tissue-specific factors. Intravasating CRC cells interact with pre-metastatic niches that are permissive for proliferation and colonization of secondary sites. The interaction of intravasating tumour cells with organ-specific microenvironment can lead to the formation of metastasis in colonised site as summarized in a later subsection (Modulation of microenvironment).

Comparing CRC to other types of cancer, its latency period between dissemination and colonization can be estimated approximately in between, since it is longer than that of lung cancer, but shorter than that of prostate cancer (64).

Metastasis-initiating ability. Critical hallmark of progression through the invasion-metastasis cascade is a metastasis-initiating ability, since disseminated tumour cells must function as founders of new metastatic colonies. They often exhibit long-term self-renewal capacity, quiescence and resistance to chemotherapy, which belong to the main traits of CSCs. CSCs have the ability to differentiate into multiple cell types found in particular metastatic samples, but represent a small fraction of the tumour population. Disseminated cells invading into the circulation are usually known as circulating tumour 
cells (CTC). CTCs consist of cells acquiring the right combination of motility, invasiveness, and resistance to anoikis (apoptosis caused by lack of attachment to neighbouring cells or extracellular matrix). There is a stochastic model saying CSCs form a small, randomly determined fraction of the CTCs, but they preferentially survive and initiate secondary tumours. On the other hand, a dynamic model hypothesis posits that CSCs undergo substantial changes in phenotype driven by responses to their microenvironment and become CTCs. After finding a target tissue, the cells extravasate, invade the target microenvironment and re-establish their stem-like properties (65).

\section{CMS classification of primary tumours and its relation to their metastasis}

A classification of a primary tumour before 2015 was based on non-overlapping genomic phenotypes of microsatellite instability (MSI) and chromosomal instability (CIN). The marked interconnectivity between independent gene expression classifiers gave rise to a classification system of CMS 1-4 groups in 2015, which do not only reflect cancer cell phenotypes nor microenvironment features present in bulk tumour tissue samples. Based on the distinct molecular and clinicopathologic hallmarks such as mutation status of KRAS, BRAF, TP53 and MSI status, each of CMS classification groups have distinct treatment pathways (66).

Previous findings in melanoma suggested that genetic instability appears to be necessary for the development of metastases (67). The observance of activated DNA repair pathways in metastases suggests that a similar metastatic program may be at play in CRC. Comparison of the transcriptomes of primary CRCs and their metastatic lesions at both the gene and pathway levels are in concordance to a study by Guinney et al (66) reporting that genetically unstable subtypes such as CMS1 and CMS3 are almost non-existent among metastases of CRC (10). CMS classification results show that metastases are more likely to be CMS2 in reference to CMS4 compared to primary tumours. Although CMS4 has previously been associated with advanced stages (III, IV) of disease, CMS2 was not previously associated with advanced disease and is characterized by epithelial differentiation and strong upregulation of MYC and WNT signalling $(10,66)$. In relation to the CMS taxonomy of CRC, tumour buds (invasive protrusions), not the tumour bulk are more related to mesenchymal phenotype and CMS4 class (29). In addition, a large CRC patient cohort analysed by IHC showed that a greater number of tumour buds were found in CMS4 compared to CMS2 and CMS3 tumours and was connected with $K R A S$ and $B R A F$ mutations $(51,68)$.

The CMS classification framework was originally developed from microarray-based gene expression profiles or RNA sequencing of fresh-frozen primary CRC samples mostly $(>90 \%)$ from patients with non-metastatic disease $(66,69)$. Some authors opposed that most CRC tumours do not have one unique and clonal CMS assignment and present an indefinite heterogeneity, and only some subclones are able to generate metastasis. The CMS classification should be a starting point to deepen our knowledge about CRC biology and the driver genes are important for metastatic progression, but it does not currently provide a rationale for therapy selection in metastatic CRC (mCRC) (69).

\section{Identification of metastatic CRC markers}

Colorectal cancer stem cells are closely linked to tumour metastasis, drug resistance and recurrence after primary treatment. Not all CSCs in primary tumour are metastatic, and metastases are produced from a specific subpopulation of CSCs, known as migrating cancer stem cells (70). Current knowledge of normal and tumour tissues indicates that CSCs are rarely defined by a single marker but by a combination of multiple molecular markers. On the other hand, several studies have linked a high surface expression of some of following markers (Table I) with the tumour degree of differentiation, depth of invasion, clinical stage and metastatic status in CRC (70-80).

Commonly used CRC cell lines show that a percentage of stem cells from intestinal origin (as indicated by LGR5 expression from 1-22.5\% and frequency of $\mathrm{EpCAM}^{+}$cells) is high in fully differentiated carcinoma cells. Sphere-derived cells showed enhanced frequencies (2- to 3-fold) of LGR5 positivity compared to the original cell lines (79). LGR5 ${ }^{+}$, E-cadherin high, EpCAM high and CD26 high are frequently associated with sphere-derived cells. These results are highlighted by a recent report showing that $\mathrm{LGR} 5^{+}$cells are more important for the process of metastasis than for primary tumour growth (81).

LGR5 is a membrane receptor of intestinal stem cells acting like local enhancer of the $\mathrm{WNT} / \beta$-catenin signalling pathway. LGR5 expression is higher in colon carcinomas than in adenomas. It correlates with TNM staging, lymph node metastases, vascular invasion and significantly lower overall survival of patients $(82,83)$.

Pang et al (36) demonstrated that a subpopulation of colorectal CSCs expressing CD26 has both tumour-initiating and metastatic capacities. Orthotopic implantation of $\mathrm{CD}_{133}{ }^{+} / \mathrm{CD} 26^{+}$cells isolated from primary CRCs of a patient with hepatic metastasis led to metastasis formation in the liver, following orthotopic tumour formation in vivo, whereas their CD26-counterparts led to no metastasis. In vitro evaluations revealed that CD26 knockdown by siRNA reduced the migratory and invasive capacities of the $\mathrm{CD} 26^{+}$cells (36). The presence of $\mathrm{CD}^{2} 6^{+} / \mathrm{CD} 326^{-}$marker in CTC tested in a CRC patient blood sample was higher in advanced Dukes' stages and was significantly associated with poor survival and high recurrence rates (84). Examination of paraffin-embedded tissues in 143 patients with CRC revealed CD26 $6^{+}$cells have a significant clinical impact on the prediction of distant metastasis development in colorectal cancer (72).

Notably, Todaro et al (85) phenotypically identified colorectal CSCs with metastatic capacity based on the expression of CD44v6. CD44v6 ${ }^{+}$cells were able to induce tumour growth in the gut, lung, and liver after orthotopic injection into mice, whereas their negative counterparts grew locally without forming distant metastases (85). Interestingly, while there was a substantial overlap between CD44v6 ${ }^{+}$and CD26 ${ }^{+}$ cells, CD44v6 $6^{+} / \mathrm{CD} 26^{-}$cells showed considerable metastatic potential in the orthotopic model (85), indicating that there is phenotypic heterogeneity even within metastatic CSCs. CD44 is involved in HGF/MET signalling and many other oncogenic mediators, including MYC and STAT3, which promote CRC metastasis via anoikis resistance and enhancing EMT properties. 
Table I. Cancer stem cell markers associated with metastases in CRC.

\begin{tabular}{|c|c|c|c|c|c|}
\hline Metastatic marker & Localisation & Interaction with & Results in & In CRC patients correlate with & h (Refs.) \\
\hline LGR5 & $\begin{array}{l}\text { Membrane } \\
\text { receptor }\end{array}$ & $\begin{array}{l}\text { R-spondin, } \\
\text { IQGAP1-Rac1 and } \\
\text { WNT signalling }\end{array}$ & $\begin{array}{l}\text { Proliferation, changes in } \\
\text { actin cytoskeletal structure } \\
\text { and cell adhesion }\end{array}$ & $\begin{array}{l}\text { TNM staging, lymph } \\
\text { node mts, vascular } \\
\text { invasion, OS }\end{array}$ & $\begin{array}{c}(71, \\
81-83)\end{array}$ \\
\hline $\begin{array}{l}\text { CD26 } \\
\text { (dipeptidyl } \\
\text { peptidase IV) }\end{array}$ & $\begin{array}{l}\text { Membrane } \\
\text { receptor }\end{array}$ & $\begin{array}{l}\text { CXCR4, CD } 45, \\
\text { adenosine deaminase, } \\
\text { fibronectin, collagen }\end{array}$ & $\begin{array}{l}\text { Motility and invasive ability } \\
\text { in vitro, mts formation } \\
\text { in vivo, modulation of } \\
\text { chemokine activity }\end{array}$ & $\begin{array}{l}\text { Distant mts formation, } \\
\text { advanced tumour staging, } \\
\text { OS }\end{array}$ & $\begin{array}{l}(34,72, \\
73,84)\end{array}$ \\
\hline CD44v6 & $\begin{array}{l}\text { Membrane } \\
\text { receptor }\end{array}$ & $\begin{array}{l}\text { HGF/c-MET, MYC, } \\
\text { STAT3, WNT } \\
\text { signalling, stabilization } \\
\text { of Cys/Glu exchange }\end{array}$ & $\begin{array}{l}\text { EMT and resistance to } \\
\text { anoikis, upregulation of } \\
M D R \text { genes, protection } \\
\text { against ROS }\end{array}$ & $\begin{array}{l}\text { Poor prognosis, resistance to } \\
\text { anti-cancer therapy-together } \\
\text { with LGR5 liver mts }\end{array}$ & $(74,85)$ \\
\hline $\begin{array}{l}\text { CD } 110 \\
\text { (thrombopoietin } \\
\text { receptor) }\end{array}$ & $\begin{array}{l}\text { Membrane } \\
\text { receptor }\end{array}$ & $\begin{array}{l}\text { Lysine degradation, } \\
\text { c-MYC, WNT } \\
\text { signalling }\end{array}$ & $\begin{array}{l}\text { Shift in redox status, } \\
\text { chromatin remodelling } \\
\text { Self-renewal and metabolic } \\
\text { re-programming in } \\
\text { CD110+ TICs. Liver mts } \\
\text { in vivo }\end{array}$ & $\begin{array}{l}\text { Grading, vascular invasion, } \\
\text { synchronous or metachronous } \\
\text { liver mts }\end{array}$ & $(87,151)$ \\
\hline $\begin{array}{l}\text { CDCP1 } \\
\text { (CUB } \\
\text { domain- } \\
\text { containing } \\
\text { protein 1) }\end{array}$ & $\begin{array}{l}\text { Membrane } \\
\text { receptor }\end{array}$ & $\begin{array}{l}\text { Enhancer of } \\
\text { Src activation }\end{array}$ & $\begin{array}{l}\text { Reduction of cell-cell } \\
\text { adhesion, raise of cell } \\
\text { migration in vitro. } \\
\text { Lung mts in vivo }\end{array}$ & $\begin{array}{l}\text { Grading, vascular invasion, } \\
\text { synchronous or metachronous } \\
\text { lung mts }\end{array}$ & $(75,87)$ \\
\hline Notch1 & Cytoplasm & TGF $\beta$ & $\begin{array}{l}\text { It creates TME of } \\
\text { poorly differentiated tumour } \\
\text { and drives metastasis via } \\
\text { TGF } \beta \text {-dependent neutrophil } \\
\text { recruitment }\end{array}$ & $\begin{array}{l}\text { Grading, LV invasion and } \\
\text { metastasis, peritumoural } \\
\text { budding }\end{array}$ & $(76,77)$ \\
\hline ALDH1A1 & Cytoplasm & $\begin{array}{l}\text { Synthesis of } \\
\text { retinoic acid, } \\
\text { activation } \\
\text { of Akt, c-Myc, RAR } \beta \text { - }\end{array}$ & $\begin{array}{l}\text { Chemoresistance, } \\
\text { clonogenicity, tumourigenicity, } \\
\text { stem cell potential } \\
\text { Regulates ROS and synthesis } \\
\text { of carboxyl acids }\end{array}$ & $\begin{array}{l}\text { Grading, LV invasion } \\
\text { and metastasis, } \\
\text { peritumoural budding } \\
\text { Poorly differentiated or RCRC } \\
\text { More ALDH1A1 in liver } \\
\text { mts vs. paired tumours }\end{array}$ & $(76,78)$ \\
\hline
\end{tabular}

Cys/Glu, cysteine/glutamate; EMT, epithelial-mesenchymal transition; HGFR, hepatocyte growth factor receptor; IQGAP1, Ras GTPase-activating-like protein; LGR5, leucine-rich repeat-containing G-protein coupled receptor 5; LV, lymphovascular; MDR, multidrug resistance; mts, metastases; Notch1, Notch homolog 1, translocation-associated; OS, overall survival; RAR $\beta$, retinoic acid receptor beta; RCRC, right-sided CRC; ROS, reactive oxygen. species, STAT3-Signal transducer and activator of transcription 3, TGF- $\beta$-Transforming growth factor beta, TICs-tumour-initiated cells, TME-tumour microenvironment.

Zhang et al showed that the CRC cell line HCT116 also contains $\mathrm{CD} 133^{+} / \mathrm{CXCR} 4^{+}$cells, which have a significantly higher metastatic capacity than $\mathrm{CD} 133^{+} / \mathrm{CXCR} 4^{-}$cells (86).

Previous findings suggested that the formation of metastases in certain favoured target organs would be attributable in part to the diversity within metastatic CSCs. Gao et al reported that only CRCs expressing CD110, a specific receptor for thrombopoietin, were able to colonize the liver after orthotopic implantation in immunocompromised mice, while CRCs expressing CUB domain-containing protein 1 (CDCP1) were associated with the development of lung metastasis (87). They also confirmed that knockdown of either CD110 or CDCP1 by siRNA reduced the liver or lung metastasis burden, respectively, but had no discernible effect on primary tumour growth. In addition, authors of that study showed that CD110 and CDCP1 would be involved in integral parts of the metastatic process, including in vivo extravasation.

Accumulating evidence suggests that alternation or even loss of differentiation control may result in complete dedifferentiation as well as acquisition of properties typical for stem cells which contribute to metastasis initiation traits. Besides known Yamanaka factors (SOX2, MYC, KLF4, OCT4, NANOG), other tissue-specific cell fate determinants essential for metastasis 
initiation responsible for metastatic relapse should be identified. The decrease of differentiation via genetic manipulation of either of two distinct differentiation-promoting transcription factors ( $\mathrm{Smad} 4$ or $\mathrm{Cdx} 2$ ) in mouse model was associated with BRAF-driven serrated tumour development and restored stem cell activity in $\mathrm{BRAF}^{\mathrm{V} 600 \mathrm{E}}$ intestine. In human patients reduced levels of differentiation in normal tissue are associated with increased susceptibility to serrated colon tumours (88).

The stem cell markers Notch1 and ALDH1 correlate with lymph node metastasis, advanced stage, and tumour recurrence and represent an independent prognostic factor in colorectal carcinoma (76). ALDH1 ${ }^{+}$cells, particularly those displaying high WNT activity, are able to initiate and maintain colon tumours when inoculated into immunodeficient mice (82). In relation to stem cell properties, much emphasis has been placed on ALDH1A1 and ALDH1A3 isoforms. Overexpression of ALDH1A3 isoform was detected in chemoresistant colorectal carcinoma cells derived from human cell line HT-29 which formed distant metastases in mouse lungs spontaneously, although the parental HT-29 colorectal cell line possesses no metastatic ability (89).

\section{Gene signature of metastatic CRC cells}

Gene signature of metastatic cells able to survive the complete metastatic cascade is derived from that of primary tumour's subclones and in CRC is based on either a chromosomal instability (CIN, 80-85\% of all CRC cases) or microsatellite instability and/or $\mathrm{CpG}$ island methylation phenotype.

Defects in mismatch repair in tumours with MSI affect MLH1, MSH2, MSH6, PMS1 and PMS2 genes (90,91). Their proteins form heterodimers that repair DNA damage. The most common and relevant heterodimers in colorectal carcinogenesis are MLH1/PMS2 and MSH2/MSH6. Immunohistochemical staining of these proteins in primary tumours and paired metastatic lesions revealed identical results in $77 \%$ (92) to $100 \%$ of the cases (93).

The CIN pathway is characterized by imbalance in the number of chromosomes, their segregation, telomere dysfunction and DNA damage response, which affect the main proliferation and cell cycle check-points: APC, KRAS, PI3K and TP53 proteins. APC mutations cause translocation of $\beta$-catenin to the nucleus and drive the transcription of genes implicated in tumourigenesis and invasion, whereas mutations in KRAS and PI3K lead to constant activation of MAP kinase, thus increasing cell proliferation. Finally, loss-of-function mutations in TP53 encoding p53, the main cell-cycle checkpoint, cause an uncontrolled entry in the cell cycle $(91,94)$. These canonical drivers are shared by primary colorectal tumours but also their paired metastases and are known as metastatic-associated early driver genes (17). Specific combination of early driver genes may confer metastatic competence. Data are in concordance with CMS classification, where the main early driver mutations consist of $A P C$, $K R A S$, TP53, PIK3CA genes in CMS2-4 tumours (95). The study of Fumagalli et al (96) triggered the $A P C, K R A S, T P 53$ and $S M A D 4$ gene in normal primary colon organoids which resulted in the seeding of metastatic cells after xenotransplantation. SMAD4 acts as a metastasis suppressor by interacting to block the functionality of transcription factors that promote metastatic cancer progression (97). In accordance with the organoid study (96), another group confirmed that oncogenic mutated KRAS combined with APC and TP53 deficiency can trigger metastatic cascade in a mouse model (98). Although the amount of canonical driver genes is low, there are many combinations of mutations that collectively disrupt key signalling pathways (WNT, TP53, TGF $\beta$, EGFP and cellular adhesion) enabling dissemination and outgrowth in distant organs.

Early CRC driver genes were supplemented with additional gene/genes from a candidate metastasis driver in numerous CRC samples: TCF7L2, AMER1, PTPRT, PIK3CA, GNAS, SRC, FXR1, MUC4, GPC6 and MECOM (99-107), which seemed to be specific to metastases (Fig. 4). Mutations in coding regions of BRCA1 and 2, FLCN, HNF1A, PTEN, $R N F 43$ leading to progression and metastases were also reported (95). Collectively, the early driver genes plus an additional candidate metastasis driver showed statistically significant enrichment in metastatic vs. early-stage CRCs (18\% compared to $5.6 \%$, respectively, $\mathrm{q}=2.9 \times 10-20)$ (17). All are connected to basic signalling pathways activated in CRC.

Transcription factor 7-like 2 (TCF7L2)-negative CRC cell lines exhibited morphological changes, enhanced migration, invasion, and collagen adhesion. Stimulation of the WNT signalling pathway leads to the association of $\beta$-catenin with BCL9, translocation to the nucleus, and association with TCF7L2, which in turn results in the activation of WNT target genes (99).

AMER1 acts as scaffold for $\beta$-catenin degradation, assembling the destruction complex at the plasma membrane by recruiting $\beta$-catenin, APC, and Axin/Conductin, and therefore acting as a key negative regulator of WNT signalling (100).

Gain-of-function mutations in PIK3CA upregulate the downstream AKT-mTOR signalling pathway thereby promoting cancer cell growth and proliferation.

By stimulating adenylyl cyclases, GNAS activation leads to intracellular accumulation of cyclic adenosine monophosphate (cAMP), a central second messenger which in turn activates protein kinase A (PKA). Similarly, $10 \%$ of CRC patients harbour gene amplification of GNAS, and another $45 \%$ have mutations in PKA subunits. There are indications that GNAS-PKA signalling is promoting growth and is connected to RAS (101).

$\mathrm{SRC}$ is non-receptor tyrosine kinase and plays a role in signalling through a variety of membrane-bound receptors. EGF and VEGFR-1-induced increase in SRC kinase activity has been shown to stimulate the movement of carcinoma cells into basement membranes. The multiple effectors of SRC include the PI3K-AKT, RAS-RAF-MAPK, STAT3-STAT5B, and p130 pathways (102).

Fragile X-related gene $1(F X R l)$ was also elevated in the plasma of colorectal cancer patients and acted as an oncogene to promote proliferation, invasion and migration of cancer cells (103). Functionally, this is likely due to FXR1 participation in an RNP complex that regulates translation in metastasis. FXR1 was also found to destabilize p21 mRNA in cancer cells, and deletion of FXR1 in these cells rescues cell cycle control (104).

Increased expression of Mucin4 (MUC4) is associated with poor survival of early-stage (I and II) CRC. The formation of the tetrameric MUC4-ErbB2-ErbB3-NRG complex leads to the hyperphosphorylation of ErbB2. This phosphorylation 


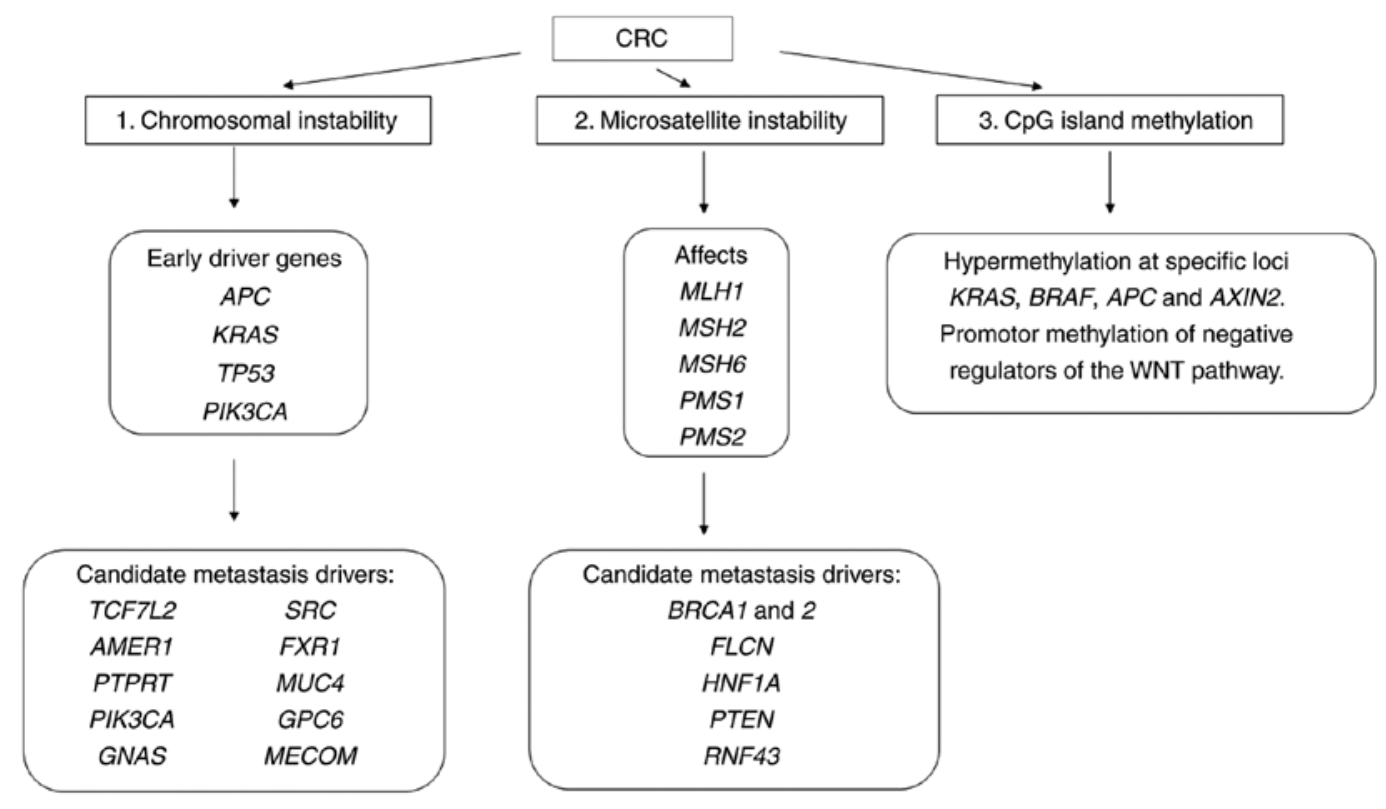

Figure 4. Genetic alterations associated with CRC metastasis. Primary CRC tumours are divided into three subgroups based on genomic phenotypes of chromosomal instability (CIN) and microsatellite instability (MSI) or epigenetic phenotype. Genetic alterations of early CRC driver genes required for transformation of an adenoma into carcinoma are supplemented with genetic/epigenetic changes in the candidate metastasis drivers to gain full metastatic competence. AMER1, APC membrane recruitment protein 1; APC, adenomatous polyposis coli; BRCA1 and 2, breast cancer type 1 and 2 susceptibility protein; FLCN, Folliculin; FXR1, f ragile X mental retardation syndrome-related protein 1; GNAS, heterotrimeric G-protein alpha subunit $\mathrm{G}_{\mathrm{s}}, \alpha$; GPC6, Glypican-6; HNF1A, hepatocyte nuclear factor 1 homeobox A; MECOM, MDS1 and EVI1 complex locus protein EVI1; MSH2, 6, MutS homolog 2, 6; MLH1, MutL homolog 1; MUC4, Mucin 4; PI3K, Phosphatidylinositol 3-kinase; PIK3CA, phosphatidylinositol-4,5-bisphosphate 3-kinase catalytic subunit alpha; PTPRT, receptor-type tyrosine-protein phosphatase T; SMAD4, Mothers against decapentaplegic homolog 4; PTEN, phosphatase and tensin homolog; TCF7L2, transcription factor 7-like 2, TP53, cellular tumour antigen p53.

enables the downstream activation of the PI3K-AKT and RAS-ERK pathways, which induce a loss of cell polarity in epithelial tumour cells as an early stem of invasion (105).

Glypican-6(GPC6) has been found to be frequently mutated and aberrantly methylated in colorectal cancer. In breast cancer progression, GPC6 effectively upregulates WNT5A signalling, which, in turn, inhibits JNK and p38 MAPK signalling, thereby promoting metastasis and invasion. In CRC patient samples, glypicans modulate WNT/ $\beta$-catenin signal pathways (106).

MECOM encodes positive regulatory domain zinc finger protein 3 (also named as PRDM3 or EVI-1) involved in downstream signalling pathway of TGF- $\beta$.

PTPRT seems to be a specific driver of the metastatic process, because its association with APC, KRAS, TP53 and SMAD4 is almost exclusively present in patients with metastases. Loss of PTPRT in CRC results in increased STAT3 activation and cellular survival. If the observations are confirmed, PTPRT mutations could be predictive biomarkers for STAT3 pathway inhibitors $(17,107)$.

In the case of CMS1 tumours the early driver genes involve two DNA repair genes MSH6 (MutS homolog 6, DNA repair gene) and $A T M$ (ATM serine/threonine kinase); negative regulator of WNT signalling RNF43 (ring finger protein 43); transforming growth factor $\beta$ receptor II; BRAF; PTEN (Phosphatase and tensin homolog) mutations and genes of microsatellite instability (95).

Metastatic cells are derived from the primary tumour's subclones, where epigenetic changes are accumulated and the EMT program is triggered. Hypermethylation at specific loci $K R A S$ and $B R A F$ leads to upregulation of the oncogenes, and promotor methylation of negative regulators of the WNT pathway lead to invasion (98). Loss of E-cadherin expression due to hypermethylation results in decreased cell-cell adhesion, tumour progression and increased invasion. EMT-promoting signals epigenetically modify the repression of epithelial genes and consequently drive the transition of cells in more mesenchymal-like states $(59,108)$.

\section{Signalling pathways involved in metastatic CRC}

Genetic changes in the driver genes together with the abovementioned candidate metastatic driver/s are reflected in a limited amount of signalling pathways, critical for cell survival and differentiation. The most important signalling pathways involved in metastatic colorectal cancer are WNT, EGFR, TGF- $\beta$ and HGF/c-MET signalling pathways (Fig. 5).

The WNT pathway plays an important role in stem cell differentiation and cellular growth, but in CRC this pathway is associated in several ways with metastasis. Concerning the metastatic process, the WNT pathway is connected with ' $\beta$-catenin paradox' in the case of CRC. The initiating event in many CRCs is represented by the constitutive activation of canonical WNT signalling through loss of function mutations of APC or gain of function of WNT agonists such as $\beta$-catenin (109). Co-activation of the Frizzled and LRP receptors prevents formation of the $\beta$-catenin destruction complex (consists of PP2A, GSK3 $\beta$, CK1 $\alpha$, APC, Axin1/2). This leads to transport of $\beta$-catenin to the nucleus, where it interacts with members of the TCF/LEF family of transcription factors and modulates the cellular functions ranging from stemness to proliferation (110). However, the nuclear localisation of $\beta$-catenin is not distributed through the tumour. IHC analysis 


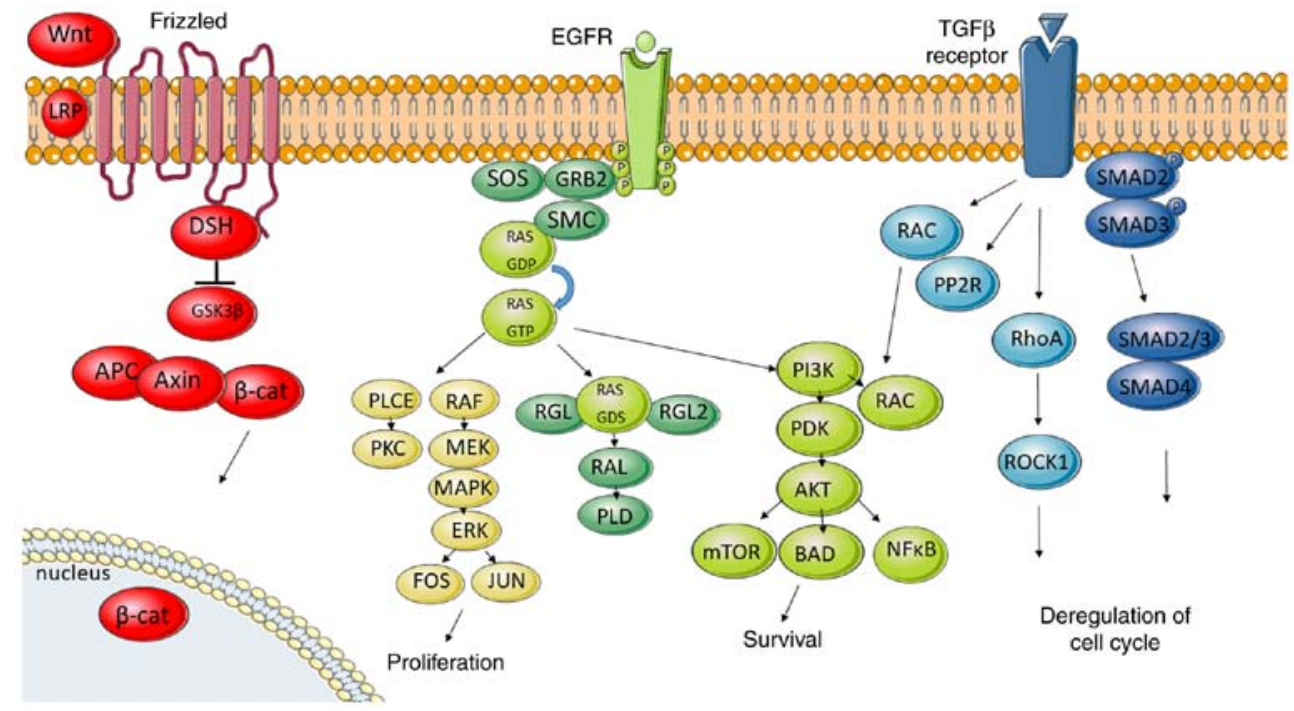

Figure 5. Signalling pathways that drive or enhance CRC metastasis. For WNT/ $\beta$-catenin, Wnt ligands, R-spondin ligands or alteration in function of APC or $\beta$-catenin lead to the integral activation of canonical WNT signalling leading to the transfer of $\beta$-catenin from the cytoplasm to the nucleus. Higher cellular stemness and proliferation together with a rise of motility and polarity are associated with activation of WNT signalling. Regarding the EGFR pathways, transformed cells accumulate constitutively active RAS proteins able to trigger downstream signalling even in the absence of extracellular signal. RAS recruits and activates several downstream effectors in different pathways: PI3K-AKT and MAPK/ERK pathways and the cascade comprising RAF kinase. All pathways contribute to the control of cell growth, differentiation, and survival. For TGF- $\beta$ signalling, activation through TGF- $\beta$ receptors results in SMAD2 and SMAD3 phosphorylation and binding to SMAD4. The complex is translocated into the nucleus to regulate the transcription of the target genes. Loss of SMAD2 and SMAD4 leads to an ability to evade apoptosis and deregulation of the cell cycle. TGF- $\beta$ activation turns on also MAPK pathways, PI3K, Notch and WNT signalling.

revealed that cells in the centre of the tumour mass are characterised by normal, membrane-bound and cytoplasmic $\beta$-catenin staining. However, cells of invasive front of CRC showed marked nuclear $\beta$-catenin accumulation in the proximity of stromal microenvironment (111). This ' $\beta$-catenin paradox' is only achieved in colon cancer cells located at the invasive front exposed to stromal signals capable of further promoting the nuclear translocation of $\beta$-catenin from the cytoplasm $(112,113)$. The same phenomenon, i.e., nuclear $\beta$-catenin staining, only in less differentiated cells located in closer proximity to the microenvironment unlike the rest of tumour mass, was previously described in colorectal metastasis (109). WNT pathway plays a role also in weakening of tight junctions, leading to reduced cellular adhesion and thus favours migration and metastasis (114).

The TGF- $\beta$ pathway is fundamental in growth, differentiation or apoptosis. Activation starts by binding TGF- $\beta$ to TGF- $\beta$ receptor 2 , which recruits TGF- $\beta$ receptor 1 . Then receptor-associated SMAD2 and SMAD3 are phosphorylated, thus allowing them to bind to SMAD4. The complex is translocated into the nucleus to regulate the transcription of the target genes (105). Chromosomal changes involving TGF- $\beta$ are connected to the CIN pathway in CRC. Loss of $18 \mathrm{q}$ is one of the main genomic aberrations related to the TGF- $\beta$ pathway in colorectal cancer (115). Chromosome 18q encodes the tumour suppressor genes SMAD2 and SMAD4, the loss of which leads to an ability to evade apoptosis and deregulation of the cell cycle. SMAD proteins act in the transcription of EMT factors. Loss of 17q-TP53 can drive tumour progression by allowing excessive proliferation $(82,116)$. Activation of the TGF- $\beta$ pathway turns on also several non-SMAD signalling pathways including MAPK, PI3K, Notch and WNT signalling (105).

Binding of growth factor to EGFR receptor induces activation of its intrinsic kinase activity recruiting Src homology 2 proteins. Adaptor protein GRB2 mobilises SOS to the membrane. Next, SOS activates GDP/GTP exchange which activates transition of RAF to the membrane. Consequently, this activates mitogen-activated protein kinase kinases 1 and 2 (MEK1 and MEK2) and subsequently activates extracellular signal-regulated kinases 1 and 2 (ERK1 and ERK2). Phosphorylated ERK then translocates to the nucleus and activates transcription factors enhancing the expression of $c-F O S$, $c$-JUN and MYC genes (25), thus promoting cell survival, proliferation, invasion, and migration $(117,118)$. Moreover, the activation of MEK1 in the RAS-RAF-MEK cascade allows the enrolment of downstream effectors EGR1 and FRA-1 which can promote the expression of SNAI1 and SNAI2, which in turn, downregulate E-cadherin expression (119). In EMT, the pathways that regulate actomyosin and cytoskeleton dynamics drive plasticity and KRAS mutations can determine the mode and effectiveness of migration by means of RhoA and Rac1 signalling $(51,120,121)$.

GRB2 also recruits the phosphoinositide 3-kinase (PI3K), another main messenger of the EGFR signalling pathway. Alterations in MAPK and PI3K pathways are involved in cell proliferation and survival. The PI3K/AKT pathway propagates signals from growth factors, cytokines, and oncogenic-mediators to contribute to CRC pathogenesis. PI3K activation leads to the production of the second messenger phosphatidylinositol-3,4,5-triphosphate which recruits a subset of signalling proteins, including phosphoinositide-dependent kinase 1 (PDK1) and AKT/protein kinase B (PKB) (27). AKT/PKB regulates several cellular processes involved in cell survival and cell cycle progression such as activating the survival factor NFK and mTOR (122). As for cell cycle progression and cell growth, several targets of AKT are involved in protein synthesis, glycogen metabolism, and cell cycle regulation (27). Loss of PTEN, which downregulates 
the PI3K pathway, was present in CRC primary tumours and their matched liver metastases and was significantly related to an increased death risk and with poor overall survival (123). BRAF mutation $\mathrm{V} 600 \mathrm{E}$ is a poor prognostic factor in metastatic cancer (124). Nevertheless, this mutation is a promising target for personalized medicine, and the combination of specific BRAF inhibitors with other MAPK/PI3K pathway inhibitors has been shown to be more effective for treating mCRC $(91,125)$. Recent evidence has shown the importance of mTORC1 and 2 pathways for mCRC. SMAD4 interacts with RICTOR to suppress mTORC2 functionality and therefore the loss of SMAD4 function results in oncogenic activation of the mTORC2 pathway, leading to enhancement in metastatic colon cancer progression. Overactivation of mTORC1 can promote tumour formation, proliferation, and metastasis, while mTORC2 can regulate the expression of mTORC1 through the mTORC2/AKT pathway $(126,127)$.

Hepatocyte growth factor (HGF) binds to cMET receptor tyrosine kinase, which is hyper-activated in primary CRC tumour development and promotes metastasis. A number of transcription factors that directly facilitate cMET expression, promote metastasis in in vivo models, and whose expression is elevated in metastatic patient samples have been identified (128). FOXC2 directly targets cMET to promote metastasis in vivo (129). The transcription factor metastasis-associated in colon cancer-1 (MACC1) (130) directly binds to the cMET promoter to enhance transcription in an $\mathrm{HGF}$-dependent manner. Findings have demonstrated that targeting MACC1 genetically or chemically reduces metastases in animal models $(131,132)$. Signalling through cMET is not only controlled by receptor expression but also by structural components that facilitate HGF ligand binding. CD44v6 acts as coreceptor and together with cMET together promotes the growth of ex vivo adenoma organoid cultures. Blocking CD44v6 or MET limited migration in vitro and reduced the metastatic spread of patient-derived tumour cells in animal models (26).

\section{Metastasis connected to the localisation of CRC}

Gene expression studies of right- and left-side colon biopsies revealed distinct expression profiles, and the researchers noted higher transcriptional activity in the descending colon (133).

Right-sided CRC (RCRC) patients tend to have advanced and larger tumours than left-sided CRC patients, where the tumours are often poorly differentiated with worse prognosis. Those tumour types usually metastasize to the peritoneal region (134). In RCRC, mutations in the DNA mismatch repair pathway are commonly observed and are detected in more advanced stages because of their flat histology. The greater proportions of the 'microsatellite unstable/immune' CMS1 and the 'metabolic' CMS3 subtypes are found in right-sided colon cancers (135). In the RCRC, the MSI or BRAF mutations are predominantly activated.

Left-sided CRC (LCRC) occurs at a younger age with metastasis to lung and liver. This type of carcinogenesis is led by chromosomal instability pathway-related mutations, such as KRAS, APC, PIK3CA, p53 mutations and they demonstrate polypoid-like morphology. While RCRC patients with $R A S$ mutation are resistant to anti-EGFR therapy, they benefit more from adjuvant chemotherapies such as 5-fluorouracil-based regimens. LCRC patients show promising results with targeted therapies such as anti-EGFR therapy and have a better prognosis. Right-sided mCRC tumours that are $R A S$ and $B R A F$ wild-type and non-bulky may respond to combination chemotherapy with anti-EGFR antibodies, but not to anti-EGFR therapy alone (136). Transverse colon tumours have mutation profiles that more closely resemble left-sided tumours, keeping right-sided tumours distinct (137). Mucinous adenocarcinomas, another type of CRC, are commonly observed in RCRC and MSI-high tumours, and are characterized by excessive mucin excretion. They also have faster progression compared to adenomatous polyps (138). There is evidence that the immune system and the microbial communities vary along the length of the colon (139).

\section{Modulation of microenvironment}

Distant tissues are normally a hostile environment for the newly arriving tumour cells. Metastatic cells are commonly attacked by the immune system, which is responsible for preventing the formation of more than $80 \%$ of metastases (140). Immune cells such as T cells, macrophages, natural killer cells and neutrophils infiltrate tumours and destroy tumour cells as part of immunosurveillance. The communication of tumour cells with the cellular compartment is recruiting new cells into the tumour microenvironment (TME) and is involved with mobilization of immune/inflammatory cells, restructuring of other tissues, altering metabolism of surrounding stroma and interruption of anti-tumour actions of the immune system (5). Tumour cells and the cells of TME can 'programme' immune cells into tumour-permissive or tumour-promoting phenotypes. EMT transcription factors, including SNAI1, ZEB1 and TGF- $\beta$ have been shown to suppress the functioning of immune system (28).

CRC tumours with microsatellite instability have a high mutational burden that creates many neoantigens that are loaded on the MHC of antigen-presenting cells and recognized as foreign by $\mathrm{T}$ cells (141). Thus, a microenvironment of MSI tumours is rich in tumour-infiltrating lymphocytes (TIL) in comparison with MSS (142) and the adaptive immune system plays an important role in suppressing tumour progression $(143,144)$. The strong activation of tumour-directed immune cells triggers the feedback expression of immune checkpoint blockade receptors and ligands, such as surface protein PD-1 and transmembrane protein PD-L1, on tumour cells, TILs and tumour-associated macrophages (145). This explains the reason for patients with MSI mCRC constituting a rare group (5\% of all cases) responsive to PD-1 blockade. However, the vast majority of mCRC patients $(95 \%)$ are microsatellite stable (MSS) with low tumour burden and a lack of immune cell infiltration, and are completely refractory to checkpoint blockade therapy, including PD-1 or PD-L1 inhibitors $(141,146,147)$. In mCRC, PD-L1-positive expression in tumour cells ranges between 22 and $38 \%$ in MSI and 13 and 67\% in MSS (148). The expression of PD-L1 in MSI tumours is localized in polarized macrophages $\left(\mathrm{CD} 163^{+}\right)$at the invasive front and in the stroma, but not in tumour cells. The quantification of $\mathrm{T}$ cells and cytotoxic $\mathrm{T}$ cells (CD3 and CD8) in mCRC tumours (immune score) shows that a higher immune score correlates with a decreased likelihood of 
metastasis (149) and can also predict the overall survival (150). However, it excludes regulatory $\mathrm{T}$ cells and inflammatory T cells (IL-17'), which have potentially important roles in CRC immunosuppression $(151,152)$.

Moreover, carcinoma cells can transform fibroblasts located at metastatic sites into CAFs known to promote metastasis (153). They do so by producing ECM niche components Periostin and Tenascin C (154). In colorectal cancer, the release of TGF- $\beta$ stimulates CAFs to secrete IL-11, which recruits carcinoma cells to activate STAT3 signalling, therefore further strengthening the ability of metastatic cells to survive in the liver (155).

Based on an analysis of $100 \mathrm{mCRC}$ patients in which NGS data yielding immune signatures were integrated with TME, clinical scores, and metabolic pathway inferences, Gastrointestinal Immune-Signature mCRC was classified into three distinct immune-metabolic clusters: Inflamed-stromal-dependent (IM Cluster 1), inflamed-non-stromal-dependent (IM Cluster 2), and non-inflamed/cold (IM Cluster 3) (152).

\section{Metabolic reprogramming in metastatic CRC}

A typical hallmark of cancer cells is their energy metabolism switch from oxidative phosphorylation to anaerobic glycolysis. Changes in cellular metabolism may precede the acquisition of driver mutations ultimately leading to colonocyte transformation. Oncogenic mutations and loss of tumour suppressor genes further reprogram CRC cells to upregulate glycolysis, glutaminolysis, one-carbon metabolism, and fatty acid synthesis (156). For example, the activation of RAS and MYC oncogenes leads to upregulation of the oxidative phosphorylation system, which is caused by MAPK activation followed by mitochondrial biogenesis induced by PGC-1 $\beta$ expression (157).

The expression profile of metabolic genes in IM Cluster 1 suggests a predominance of the aerobic glycolytic pathway over oxidative mitochondrial TCA (Krebs) cycle with lactate-mediated TME acidification. IM Cluster II is associated with immune (T, NK and B cells) and myeloid-monocytes with enrichment for immune checkpoint genes and features of EMT. The cluster underwent a distinctive metabolic reprogramming with enhanced TCA oxidative phosphorylation and glutaminolysis. IM Cluster 3 is characterized by the absence of myeloid-derived suppressor cells, T-regulation and CAF markers. Glycolytic tumour cell metabolism limits glucose availability in the TME, which, coupled with high lactate excretion and extracellular acidification rate, can potentially dampen $\mathrm{CD}^{+} \mathrm{T}$-cell differentiation and function (158).

Upregulation of glycolytic genes and glycolytic capacity was also detected in mCRC. Specifically, glucose transporter 1 and 3 (GLUT1 and GLUT3) overexpression was associated with metastasis and poor survival in colorectal cancer patients. In detail, hypoxia-inducible factor- $1 \alpha$ (HIF-1 $\alpha)$ is activated in cultured HCT116 colon cancer cells under hypoxic conditions as well as in tumour budding cells of CRC (159). Hypoxia and HIF-1 $\alpha$ upregulate cancer cell expression of GLUT1 and induce glycogen metabolizing enzymes $(160,161)$. Additionally, GLUT3 promotes invasiveness and stemness in a Yes-associated protein (YAP)-dependent manner. Activation of YAP in turn transactivated GLUT3 and regulated a group of glycolytic genes. Importantly, a high-fat high-sucrose diet promoted tumour metastasis, whereas the inhibition of either GLUT3 or YAP effectively reduced the metastatic burden. Activation of the GLUT3-YAP signalling pathway acts as a master activator to reprogram cancer metabolism and thereby promotes metastasis (162).

Reservoirs of nutrients and oxygen vary between different host organs. The lungs are rich in glucose and oxygen supplies, which may grant easier colonization of metastatic cells using aerobic glycolysis (163) or oxidative phosphorylation (164). In stark contrast, the liver has lower levels of oxygen and irregular glucose availability which indicates that metastatic cells in this organ need to urgently adapt to such metabolic stresses (56). In addition, metastatic cells may use other sources of energy than primary tumour cells. Indeed, aerobic glycolysis observed in primary tumours is often replaced by other types of energy production in metastasis (165). In other organs with low oxygen tension, metastatic cells are able to use the creatine cycle to scavenge ATP or activate $\beta$-oxidation (56). According to $\mathrm{Bu}$ et al colon cancer-derived liver metastases upregulate Aldolase-B, an enzyme for fructose metabolism that utilizes fructose as a source of energy. Targeting Aldolase-B or its upstream regulator GATA6 or reduction of fructose decreases liver metastatic growth (166). A detachment of tumour cells from the extracellular matrix during metastasis also reduces glucose uptake (164).

Moreover, metastatic colorectal $\mathrm{CD} 110^{+}$cancer cells in liver can utilize thrombopoietin-mediated activation of lysine degradation. The mechanism of action is based on lysine catabolism leading to activated WNT signalling and a shift in redox status (167).

\section{Effect of microRNAs on the metastatic process of CRC}

Dysregulation and aberrant expression of microRNAs (miRNAs) has been found in various types of cancer including colorectal cancer (up to 35 miRNAs) (165). This makes them potential biomarkers for predicting prognosis, characterisation of the tumour and a tool for diagnosis. Dysregulation can be explained by various genetic alterations and epigenetic modifications such as methylation (168).

MiRNAs can have an opposite effect on tumour progression by targeting oncogenes while acting as tumour suppressors. While being downregulated, they can serve as biomarkers for early diagnosis. MiR-19 (169), miR-885-5p (170) and miR-155 (171) were associated with induction of migration and invasion of CRC cells. MiR-21 augments invasion and migration by downregulating tumour suppressor gene PDCD4 (172).

A study by Loo et al (173) has also underlined the necessity of CRC cells to get energy from the extracellular environment to overcome metabolic stress in liver. In that study, colon cancer cells, by downregulating miR-483 and miR-551, derepressed and secreted creatine kinase brain type into the extracellular space. The cancer cells benefit from elevated levels of creatine in the liver, which is converted into phosphocreatine to serve as an ATP source for growth functions in metastatic cells (174).

Post-transcriptional regulation of gene expression by EMT-related miRNAs showed a great impact on promoting the epithelial or mesenchymal phenotype of CRC cells targeting specific mRNA (173). Some miRNAs can regulate 
genes involved in EMT thereby regulating the early steps of metastasis formation in CRC, for example, miR-31-5p targets and inhibits c-MET, a mediator of EMT (175). Other miRNAs that are target mediators of EMT are miR-34 which targets c-MET, SNAI1 and $\beta$-catenin (176), miR-302 which targets AP4, SNAI1 and vimentin (177), and miR-15a functioning similarly to miR302 and targeting AP4 (178). Altered expression of miRNA affects the expression of Cadherin-1 and EMT transcription factors. For example, the expression of miR-508 negatively correlates with stemness and EMT-associated gene expression and positively correlates with patient survival in colorectal cancer (179).

Members of the miR-200 family (miR-200a, miR-200b, miR-200c, miR-141, and miR-429) promote epithelial phenotype preventing the translation of ZEB1 and ZEB2 mRNA (180). This, in turn, acts in a negative feedback loop downregulating the miR-200 family expression (62). Moreover, ZEB2 is also identified as a direct target of miR-132, miR-192, and miR-335. Downregulation of these miRNAs is usually associated with the acquisition of an aggressive mesenchymal phenotype leading to distant metastasis and a poor prognosis $(181,182)$. MiR-34a/b/c is another caretaker of the epithelial phenotype through the downregulation of SNAI1, SNAI2 and ZEB1 (183). Suppression of $\mathrm{miR}-34 \mathrm{a} / \mathrm{b} / \mathrm{c}$ causes upregulation of SNAI1 resulting in the enhanced expression of EMT markers, mesenchymal features, and improved cell invasion and motility (51). Targeting of this overexpressed miRNA associated with metastasis can improve the overall survival of CRC patients.

\section{Epigenetic changes in metastatic CRC}

Proto-oncogenes and tumour suppressors can be affected not only by genetic but also by epigenetic alternations. Inactivation of tumour suppressor genes can affect apoptosis, invasion and cell proliferation (184). For example, a tumour suppressor gene termed $N-M Y C$ downstream-regulated gene 1 in a highly metastatic cell line SW620 is silenced by reduced H4 acetylation (185).

Aberrant DNA methylation has also been extensively demonstrated in CRC and occurs early in the adenoma to carcinoma sequence, as the hypermethylation in the gene promoters transcriptionally silences the tumour suppressor genes $(9,186)$. The $\mathrm{CpG}$ island methylator phenotype pathway in CRC is characterized by significant changes in promoter methylation (179). Loss of E-cadherin expression is caused by hypermethylation and results in decreased cell-cell adhesion, tumour progression and increased invasion (187).

Changes in metabolic flux impact epigenetics in both normal and cancer cells because metabolites serve as essential cofactors for chromatin remodelling enzymes responsible for epigenetic alterations $(188,189)$. S-adenosyl methionine (SAM), generated by the methionine cycle, serves as the methyl donor for histone methyltransferases and DNA-methyltransferases (188). Thus, changes in intracellular SAM levels directly affect histone methylation associated with active gene transcription (190). On the other hand, CRC also exhibits global DNA hypomethylation outside of $\mathrm{CpG}$ islands (191). Metabolites generated in the citric acid cycle and electron transfer chain serve as cofactors for DNA and histone demethylation. Alpha ketoglutarate is required for activity of the TET (Ten-eleven translocation methylcytosine dioxygenase 1) family of DNA demethylases and the Jumonji C family of histone demethylases $(148,188)$.

A variety of chromatin remodelling complexes play a central role in the transcriptional regulation of EMT-related transcription factors and microRNAs by determining the accessibility of regulatory DNA elements and positioning of nucleosomes $(58,59)$. In addition, post-translational histone modifications modulate chromatin folding, influence the recruitment of regulatory proteins and control gene expression (192). Accordingly, contextual EMT-promoting signals epigenetically modify the repression of epithelial genes and consequently drive the transition of cells in more mesenchymal-like states. These are epigenetically sustained unless the presence of EMT-promoting signals is discontinued leading to reversion to more epithelial phenotypes $(59,108)$. However, the heterogeneity of metastatic cancer cells represents a difficulty in specifying epigenetic background of these cells.

\section{Conclusion}

This review has demonstrated a growing understanding of biological and molecular traits of metastatic colorectal cells and describes molecular drivers and enhancers of metastasis in CRC. A central core property of metastatic cells is their cellular plasticity, which underlies almost all other hallmarks: Motility, invasiveness, the ability to degrade components of the extracellular matrix, ability to colonise distinct organs and the metastasis-initiating ability. Disseminated cancer cells display intermediate phenotypes featuring both epithelial and mesenchymal characteristics depending on changing conditions within the metastatic cascade. The ability to modulate the local microenvironment is based on strong activation of tumour-directed immune cells and blockade of their receptors and ligands. After the process of intravasation, the metastatic cells inclined from invasive properties back to their proliferative potential and ability to differentiate into more cell types to form macrometastasis.

The genetic and molecular determinants of metastatic competence and active molecular pathways mimic the changing metastatic traits. Nevertheless, knowledge of the dynamics of transcriptional and metabolic changes in disseminated cells, CTC and intravasated cells on the RNA, protein and pathway level is limited by the current technical possibilities. However, the genomic landscape of mCRC together with expression profiles have led to the identification of driver genetic events in metastatic development. The effect of mutations on early driver genes including APC, KRAS, TP53, PIK3CA in CMS 2-4 tumour (95) is increased by one or more candidate metastasis drivers: TCF7L2, AMER1, PTPRT, PIK3CA, GNAS, SRC, FXR1, MUC4, GPC6 and MECOM (17). They encode regulators of signalling pathways: WNT signalling pathway (TCF7L2, AMER1), activator of cAMP and protein kinase A (GNAS), PI3K-Akt, and AKT-mTOR signalling pathway (PIK3CA), PI3K-Akt, Ras-Raf-MAPK, STAT3/STAT5B, and p130 pathways (SRC), the PI3K-Akt and Ras-ERK pathways (Mucin4), JNK and p38 MAPK signalling (Glypican 4 ) and TGF- $\beta$ pathway (MECOM). The overproduction, abrogation or incorrect location of proteins encoded by these genes and their combination dysregulate many pivotal signalling pathways enabling the dissemination and outgrowth in distant organs. In addition, epigenetic mechanisms 
and metabolic reprogramming play significant roles in driving tumour progression towards the metastatic process.

\section{Acknowledgements}

We would like to thank Martin Benej, PhD, for language editing.

\section{Funding}

This study was supported by VEGA (grant nos. 2/0128/17, 2/0050/19 and 2/0124/17); by the Ministry of Health of the Slovak Republic under the contract 2019/60-BMCSAV and by funding from the European Union's Horizon 2020 Research and Innovation Strategies to Programme under grant agreement no. 857381 (project VISION).

\section{Availability of data and materials}

Not applicable.

\section{Authors' contributions}

MP, TF, SB, SS, LK, and MM contributed to this paper with conception of the study, literature review and analysis. MP prepared the figures. All authors read and approved the final version of the manuscript.

\section{Ethics approval and consent to participate}

Not applicable.

\section{Patient consent for publication}

Not applicable.

\section{Competing interests}

The authors declare that they have no competing interests.

\section{References}

1. Dekker E, Tanis PJ, Vleugels JLA, Kasi PM and Wallace MB: Colorectal cancer. Lancet 394: 1467-1480, 2019.

2. Bray F, Ferlay J, Soerjomataram I, Siegel RL, Torre LA and Jemal A: Global cancer statistics 2018: GLOBOCAN estimates of incidence and mortality worldwide for 36 cancers in 185 countries. CA Cancer J Clin 68: 394-424, 2018.

3. Qiu M, Hu J, Yang D, Cosgrove DP and Xu R: Pattern of distant metastases in colorectal cancer: A SEER based study. Oncotarget 6: 38658-38666, 2015.

4. Zarour LR, Anand S, Billingsley KG, Bisson WH, Cercek A, Clarke MF, Coussens LM, Gast CE, Geltzeiler CB, Hansen L, et al: Colorectal cancer liver metastasis: Evolving paradigms and future directions. Cell Mol Gastroenterol Hepatol 3: 163-173, 2017.

5. Welch DR and Hurst DR: Defining the hallmarks of metastasis. Cancer Res 79: 3011-3027, 2019.

6. Lambert AW, Pattabiraman DR and Weinberg RA: Emerging biological principles of metastasis. Cell 168: 670-691, 2017.

7. Hirata A, Hatano Y,Niwa M, Hara A and Tomita H: Heterogeneity of colon cancer stem cells. Adv Exp Med Biol 1139: 115-126, 2019.

8. Tauriello DV, Calon A, Lonardo E and Batlle E: Determinants of metastatic competency in colorectal cancer. Mol Oncol 11: 97-119, 2017
9. Puccini A, Xiu J, Goldberg RM, Grothey A, Shields AF, Salem ME, Seeber A, Battaglin F, Berger MD, El-Deiry WS, et al: Molecular differences between lymph nodes (LNs) and distant metastases (mets) in colorectal cancer (CRC). J Clin Oncol 37 (Suppl 15): S3130, 2019.

10. Kamal Y, Schmit SL, Hoehn HJ, Amos CI and Frost HR: Transcriptomic differences between primary colorectal adenocarcinomas and distant metastases reveal metastatic colorectal cancer subtypes. Cancer Res 79: 4227-4241, 2019.

11. Pretzsch E, Bösch F, Neumann J, Ganschow P, Bazhin A, Guba M, Werner J and Angele M: Mechanisms of metastasis in colorectal cancer and metastatic organotropism: Hematogenous versus peritoneal spread. J Oncol 2019: 7407190, 2019.

12. Tariq K and Ghias K: Colorectal cancer carcinogenesis: A review of mechanisms. Cancer Biol Med 13: 120-135, 2016.

13. Ramaswamy S, Ross KN, Lander ES and Golub TR: A molecular signature of metastasis in primary solid tumors. Nat Genet 33: 49-54, 2003.

14. Naxerova K and Jain RK: Using tumour phylogenetics to identify the roots of metastasis in humans. Nat Rev Clin Oncol 12: $258-272,2015$

15. Meacham CE and Morrison SJ: Tumour heterogeneity and cancer cell plasticity. Nature 501: 328-337, 2013.

16. Sottoriva A, Kang H, Ma Z, Graham TA, Salomon MP, Zhao J, Marjoram P, Siegmund K, Press MF, Shibata D and Curtis C: A big bang model of human colorectal tumor growth. Nat Genet 47: 209-216, 2015.

17. Hu Z, Ding J, Ma Z, Sun R, Seoane JA, Scott Shaffer J, Suarez CJ, Berghoff AS, Cremolini C, Falcone A, et al: Quantitative evidence for early metastatic seeding in colorectal cancer. Nat Genet 51: 1113-1122, 2019.

18. Holch JW, Ricard I, Stintzing S, Modest DP and Heinemann V: The relevance of primary tumour location in patients with metastatic colorectal cancer: A meta-analysis of first-line clinical trials. Eur J Cancer 70: 87-98, 2017.

19. Auguste P, Fallavollita L, Wang N, Burnier J, Bikfalvi A and Brodt P: The host inflammatory response promotes liver metastasis by increasing tumor cell arrest and extravasation. Am J Pathol 170: 1781-1792, 2007.

20. Riihimäki M,Hemminki A, Sundquist J and Hemminki K: Patterns of metastasis in colon and rectal cancer. Sci Rep 6: 29765, 2016.

21. Prasanna T, Craft PS, Chua YJ, Karapetis CS, Gibbs P, Wong R, Tie J, Roder DM, Price TJ, Padbury R, et al: The outcome of patients (pts) with metastatic colorectal cancer (mCRC) based on site of metastases (mets) and the impact of molecular markers and site of primary cancer on metastatic pattern. J Clin Oncol 35 (Suppl 15): S3560, 2017.

22. Sadahiro S, Suzuki S, Ishikawa K, Nakamura T, Tanaka Y, Ishizu K, Yasuda S, Makuuchi H and Murayama C: Estimation of the time of pulmonary metastasis in colorectal cancer patients with isolated synchronous liver metastasis. Jpn J Clin Oncol 35: 18-22, 2005.

23. Liu J, Wang D, Zhang C, Zhang Z, Chen X, Lian J, Liu J, Wang G, Yuan W, Sun Z, et al: Identification of liver metastasis-associated genes in human colon carcinoma by mRNA profiling. Chin $\mathrm{J}$ Cancer Res 30: 633-646, 2018.

24. Schweiger T, Liebmann-Reindl S, Glueck O, Starlinger P, Laengle J, Birner P, Klepetko W, Pils D, Streubel B and Hoetzenecker K: Mutational profile of colorectal cancer lung metastases and paired primary tumors by targeted next generation sequencing: Implications on clinical outcome after surgery. J Thorac Dis 10: 6147-6157, 2018.

25. Hugen N, van de Velde CJH, de Wilt JHW and Nagtegaal ID: Metastatic pattern in colorectal cancer is strongly influenced by histological subtype. Ann Oncol 25: 651-657, 2014.

26. Andres SF, Williams KN and Rustgi AK: The molecular basis of metastatic colorectal cancer. Curr Colorectal Cancer Rep 14: 69-79, 2018.

27. Hanahan D and Weinber RA: The hallmark of cancer. Cell 100: 57-70, 2000.

28. Hanahan D and Weinber RA: The hallmarks of cancer: The next generation. Cell 144: 646-674, 2011.

29. De Smedt L, Palmans S, Andel D, Govaere O, Boeckx B, Smeets D, Galle E, Wouters J, Barras D, Suffiotti M, et al: Expression profiling of budding cells in colorectal cancer reveals an EMT-like phenotype and molecular subtype switching. Br J Cancer 116: 58-65, 2017.

30. Cheung KJ, Gabrielson E, Werb Z and Ewald AJ: Collective invasion in breast cancer requires a conserved basal epithelial program. Cell 155: 1639-1651, 2013. 
31. Revenu C and Gilmour D: EMT 2.0: Shaping epithelia through collective migration. Curr Opin Genet Dev 19: 338-342, 2009.

32. Westcott JM, Prechtl AM, Maine EA, Dang TT, Esparza MA, Sun H, Zhou Y, Xie Y and Pearson GW: An epigenetically distinct breast cancer cell subpopulation promotes collective invasion. J Clin Invest 125: 1927-1943, 2015.

33. Ye X, Tam WL, Shibue T, Kaygusuz Y, Reinhardt F, Ng Eaton E and Weinberg RA: Distinct EMT programs control normal mammary stem cells and tumour-initiating cells. Nature 525: 256-260, 2015

34. Brabletz T, Hlubek F, Spaderna S, Schmalhofer O, Hiendlmeyer E, Jung A and Kirchner T: Invasion and metastasis in colorectal cancer: Epithelial-mesenchymal transition, mesenchymal-epithelial transition, stem cells and beta-catenin. Cells Tissues Organs 179: 56-65, 2005.

35. Fan F, Samuel S, Evans KW, Lu J, Xia L, Zhou Y, Sceusi E, Tozzi F, Ye XC, Mani SA and Ellis LM: Overexpression of snail induces epithelial-mesenchymal transition and a cancer stem cell-like phenotype in human colorectal cancer cells. Cancer Med 1: 5-16, 2012.

36. Pang R, Law WL, Chu AC, Poon JT, Lam CS, Chow AK, Ng L, Cheung LW, Lan XR, Lan HY, et al: A subpopulation of CD26 cancer stem cells with metastatic capacity in human colorectal cancer. Cell Stem Cell 6: 603-615, 2010.

37. Nakano M, Kikushige Y, Miyawaki K, Kunisaki Y, Mizuno S, Takenaka K, Tamura S, Okumura Y, Ito M, Ariyama H, et al: Dedifferentiation process driven by TGF-beta signaling enhances stem cell properties in human colorectal cancer. Oncogene 38 : 780-793, 2019.

38. Watanabe T, Kobunai T, Yamamoto Y, Matsuda K, Ishihara S, Nozawa K, Iinuma H, Kanazawa T, Tanaka T, Konishi T, et al: Gene expression of mesenchyme forkhead 1 (FOXC2) significantly correlates with the degree of lymph node metastasis in colorectal cancer. Int J Surg 96: 207-216, 2011.

39. Sánchez-Tilló E, de Barrios O, Siles L, Cuatrecasas M Castells A and Postigo A: $\beta$-catenin/TCF4 complex induces the epithelial-to-mesenchymal transition (EMT)-activator ZEB1 to regulate tumor invasiveness. Proc Natl Acad Sci USA 108 : 19204-19209, 2011.

40. Han X, Fang X, Lou X, Hua D, Ding W, Foltz G, Hood L, Yuan Y and Lin B: Silencing SOX2 induced mesenchymal-epithelial transition and its expression predicts liver and lymph node metastasis of CRC patients. PLoS One 7: e41335, 2012.

41. Dai X, Ge J, Wang X, Qian X, Zhang C and Li X: OCT4 regulates epithelial-mesenchymal transition and its knockdown inhibits colorectal cancer cell migration and invasion. Oncol Rep 29: $155-160,2013$.

42. Meng HM, Zheng P, Wang XY, Liu C, Sui HM, Wu SJ, Zhou J, Ding YQ and Li J: Over-expression of Nanog predicts tumor progression and poor prognosis in colorectal cancer. Cancer Biol Ther 9: 295-302, 2010.

43. Lu MH, Huang CC, Pan MR, Chen HH and Hung WC: Prospero homeobox 1 promotes epithelial-mesenchymal transition in colon cancer cells by inhibiting E-cadherin via miR-9. Clin Cancer Res 18: 6416-6425, 2012.

44. Ono H, Imoto I, Kozakiet K, Tsuda H, Matsui T, Kurasawa Y, Muramatsu T, Sugihara K and Inazawa J: SIX1 promotes epithelial-mesenchymal transition in colorectal cancer through ZEB1 activation. Oncogene 31: 4923-4934, 2012.

45. Takahashi Y, Sawada G, Kurashige J, Uchi R, Matsumura T, Ueo H Takano Y, Akiyoshi S, Eguchi H, Sudo T, et al: Paired related homoeobox 1, a new EMT inducer, is involved in metastasis and poor prognosis in colorectal cancer. Br J Cancer 109: 307-311, 2013.

46. Belton A, Gabrovsky A, Bae YK, Reeves R, Iacobuzio-Donahue C, Huso DL and Resar LM: HMGA1 induces intestinal polyposis in transgenic mice and drives tumor progression and stem cell properties in colon cancer cells. PLoS One 7: e30034, 2012.

47. Diesch J, Sanij E, Gilan O, Love C, Tran H, Fleming NI, Ellul J, Amalia M, Haviv I, Pearson RB, et al: Widespread FRA1-dependent control of mesenchymal transdifferentiation programs in colorectal cancer cells. PLoS One 9: e88950, 2014.

48. Toiyama Y, Yasuda H, Saigusa S, Tanaka K, Inoue Y, Goel A and Kusunoki M: Increased expression of Slug and Vimentin as novel predictive biomarkers for lymph node metastasis and poor prognosis in colorectal cancer. Carcinogenesis 34: 2548-2557, 2013.

49. Janda E, Lehmann K, Killisch I, Jechlinger M, Herzig M, Downward J, Beug H and Grünert S: Ras and TGF[beta] cooperatively regulate epithelial cell plasticity and metastasis: Dissection of Ras signaling pathways. J Cell Biol 156: 299-313, 2002.
50. Gotzmann J, Mikula M, Eger A, Schulte-Hermann R, Foisner R, Beug $\mathrm{H}$ and Mikulitz W: Molecular aspects of epithelial cell plasticity: Implications for local tumor invasion and metastasis. Mutat Res 566: 9-20, 2004

51. Maffeis V, Nicolè L and Cappellesso R: RAS, cellular plasticity, and tumor budding in colorectal cancer. Front Oncol 9: 1255, 2019.

52. Wan Z, Chai R, Yuan H, Chen B, Dong Q, Zheng B, Mou X, Pan W, Tu Y, Yang Q, et al: MEIS2 promotes cell migration and invasion in colorectal cancer. Oncol Rep 42: 213-223, 2019.

53. Sugai T, Yamada N, Eizuka M, Sugimoto R, Uesugi N, Osakabe M, Ishida K, Otsuka K, Sasaki A and Matsumoto T: Vascular invasion and stromal S100A4 expression at the invasive front of colorectal cancer are novel determinants and tumor prognostic markers. J Cancer 8: 1552-1561, 2017.

54. Varga $\mathbf{J}$ and Greten FR: Cell plasticity in epithelial homeostasis and tumorigenesis. Nat Cell Biol 19: 1133-1141, 2017.

55. Ishay-Ronen D, Diepenbruck M, Kalathur RKR, Sugiyama N, Tiede S, Ivanek R, Bantug G, Morini MF, Wang J, Hess C and Christofori G: Gain fat-lose metastasis: Converting invasive breast cancer cells into adipocytes inhibits cancer metastasis. Cancer Cell 35: 17-32.e6, 2019.

56. Nieto MA, Huang RY, Jackson RA and Thiery JP: EMT: 2016. Cell 166: 21-45, 2016.

57. Celià-Terrassa $T$ and Kang Y: Distinctive properties of metastasis-initiating cells. Genes Dev 30: 892-908, 2016.

58. Tam WL and Weinberg RA: The epigenetics of epithelial-mesenchymal plasticity in cancer. Nat Med 19: 1438-1449, 2013.

59. Mohd-Sarip A, Teeuwssen M, Bot AG, De Herdt MJ, Willems SM, Baatenburg de Jong RJ, Looijenga LHJ,Zatreanu D, Bezstarosti K, van Riet J, et al: DOC1-dependent recruitment of NURD reveals antagonism with SWI/SNF during epithelial-mesenchymal transition in oral cancer cells. Cell Rep 20: 61-75, 2017.

60. Pastushenko I and Blanpain C: EMT transition states during tumor progression and metastasis. Trends Cell Biol 29: 212-226, 2019.

61. Liu S, Cong Y, Wang D, Sun Y, Deng L, Liu Y, Martin-Trevino R, Shang L, McDermott SP, Landis MD, et al: Breast cancer stem cells transition between epithelial and mesenchymal states reflective of their normal counterparts. Stem Cell Report 2: 78-91, 2013.

62. Biddle A, Gammon L, Liang X, Costea DE and Mackenzie IC: Phenotypic plasticity determines cancer stem cell therapeutic resistance in oral squamous cell carcinoma. EBioMedicine 4: 138-145, 2016.

63. Katsuno Y, Meyer DS, Zhang Z, Shokat KM, Akhurst RJ, Miyazono K and Derynck R: Chronic TGF- $\beta$ exposure drives stabilized EMT, tumor stemness, and cancer drug resistance with vulnerability to bitopic mTOR inhibition. Sci Signal 12: eaau8544, 2019.

64. Obenauf AC and Massagué J: Surviving at a distance: Organ specific metastasis. Trends Cancer 1: 76-91, 2015.

65. Agnoletto C, Corrà F, Minotti L, Baldassari F, Crudele F, Cook WJJ, Di Leva G, d'Adamo AP, Gasparini P and Volinia S: Heterogeneity in circulating tumor cells: The relevance of the stem-cell subset. Cancers (Basel) 11: 483, 2019.

66. Guinney J, Dienstmann R, Wang X, de Reyniès A, Schlicker A, Soneson C, Marisa L, Roepman P, Nyamundanda G, Angelino P, et al: The consensus molecular subtypes of colorectal cancer. Nat Med 21: 1350-1356, 2015.

67. Kauffmann A, Rosselli F, Lazar V, Winnepenninckx V, Mansuet-Lupo A, Dessen P, van den Oord JJ, Spatz A and Sarasin A: High expression of DNA repair pathways is associated with metastasis in melanoma patients. Oncogene 27: 565-573, 2008.

68. Trinh A, Lädrach C, Dawson HE, Ten Hoorn S, Kuppen PJ, Reimers MS, Koopman M, Punt CJ, Lugli A, Vermeulen L and Zlobec I: Tumour budding is associated with the mesenchymal colon cancer subtype and RAS/RAF mutations: A study of 1320 colorectal cancers with consensus molecular subgroup. Br J Cancer 119: 1244-1251, 2018

69. Sveen A, Cremolini C and Dienstmann R: Predictive modeling in colorectal cancer: Time to move beyond consensus molecular subtypes. Ann Oncol 30: 1682-1685, 2019.

70. Zhou Y, Xia L, Wang H, Oyang L, Su M, Liu Q, Lin J, Tan S, Tian Y, Liao Q and Cao D: Cancer stem cells in progression of colorectal cancer. Oncotarget 9: 33403-33415, 2017.

71. Carmon KS, Gong X, Yi J, Wu L, Thomas A, Moore CM, Masuho I, Timson DJ, Martemyanov KA and Liu QJ: LGR5 receptor promotes cell-cell adhesion in stem cells and colon cancer cells via the IQGAP1-Racl pathway. J Biol Chem 292: 14989-15001, 2017. 
72. Lam CS, Cheung AH, Wong SK, Wan TM, Ng L, Chow AK, Cheng NS, Pak RC, Li HS, Man JH, et al: Prognostic significance of CD26 in patients with colorectal cancer. PLoS One 9: e98582, 2014.

73. Mortier A, Gouwy M, Van Damme J, Proost P and Struyf S: CD26/dipeptidylpeptidase IV-chemokine interactions: Double-edged regulation of inflammation and tumor biology. J Leukoc Biol 99: 955-969, 2016.

74. Ma L, Dong L and Chang P: CD44v6 engages in colorectal cancer progression. Cell Death Dis 10: 30, 2019.

75. Liu H, Ong SE, Badu-Nkansah K, Schindler J, White FM and Hynes RO: CUB-domain-containing protein 1 (CDCP1) activates Src to promote melanoma metastasis. Proc Natl Acad Sci USA 108: 1379-1384, 2011.

76. Mohamed SY, Kaf RM, Ahmed MM, Elwan A, Ashour HR and Ibrahim A: The prognostic value of cancer stem cell markers (Notch1, ALDH1, and CD44) in primary colorectal carcinoma. J Gastrointest Cancer 50: 824-837, 2019.

77. Jackstadt R, van Hooff SR, Leach JD, Cortes-Lavaud X, Lohuis JO, Ridgway RA, Wouters VM, Roper J, Kendall TJ, Roxburgh CS, et al: Epithelial NOTCH signaling rewires the tumor microenvironment of colorectal cancer to drive poor-prog nosis subtypes and metastasis. Cancer Cell 36: 319-336.e7, 2019.

78. Van der Waals LM, Borel Rinkes IH and Kranenburg O: ALDH1A1 expression is associated with poor differentiation, 'right-sidedness' and poor survival in human colorectal cancer. PLoS One 13: e0205536, 2018

79. Vázquez-Iglesias L, Barcia-Castro L, Rodríguez-Quiroga M, Páez de la Cadena M, Rodríguez-Berrocal J and Cordero OJ: Surface expression marker profile in colon cancer cell lines and sphere-derived cells suggests complexity in CD26 ${ }^{+}$cancer stem cells subsets. Biol Open 8: bio041673, 2019.

80. Dotse E and Bian Y: Isolation of colorectal cancer stem-like cells. Cytotechnology 68: 609-619, 2016.

81. De Sousa E Melo F, Wang X, Jansen M, Fessler E, Trinh A, de Rooij LP, de Jong JH, de Boer OJ, van Leersum R, Bijlsma MF, et al: Poor-prognosis colon cancer is defined by a molecularly distinct subtype and develops from serrated precursor lesions. Nat Med 19: 614-618, 2013.

82. Testa U, Pelosi E and Castelli G: Colorectal cancer: Genetic abnormalities, tumor progression, tumor heterogeneity, clonal evolution and tumor-initiating cells. Med Sci (Basel) 6: 31, 2018

83. Fedyanin M, Popova A, Polyanskaya E and Tjulandin S: Role of stem cells in colorectal cancer progression and prognostic and predictive characteristics of stem cell markers in colorectal cancer. Curr Stem Cell Res Ther 12: 19-30, 2017.

84. Lieto E, Galizia G, Orditura M, Romano C, Zamboli A Castellano P, Mabilia A, Auricchio A, De Vita F and Gemei M CD26-positive/CD326-negative circulating cancer cells as prognostic markers for colorectal cancer recurrence. Oncol Lett 9 : 542-550, 2015.

85. Todaro M, Gaggianesi M, Catalano V, Benfante A, Iovino $\mathrm{F}$ Biffoni M, Apuzzo T, Sperduti I, Volpe S, Cocorullo G, et al: $\mathrm{CD} 44 \mathrm{v} 6$ is a marker of constitutive and reprogrammed cancer stem cells driving colon cancer metastasis. Cell Stem Cell 14: 342-356, 2014

86. Zhang SS, Han ZP, Jing YY, Tao SF, Li TJ, Wang H, Wang Y, Li R, Yang Y, Zhao X, et al: CD133(+)CXCR4(+) colon cancer cells exhibit metastatic potential and predict poor prognosis of patients. BMC Med 10: 85, 2012.

87. Gao W, Chen L, Ma Z, Du Z, Zhao Z, Hu Z and Li Q: Isolation and phenotypic characterization of colorectal cancer stem cells with organ-specific metastatic potential. Gastroenterology 145 636-646.e5, 2013

88. Tong K, Pellón-Cárdenas O, Sirihorachai VR, Warder BN, Kothari OA, Perekatt AO, Fokas EE, Fullem RL, Zhou A, Thackray JK, et al: Degree of tissue differentiation dictates susceptibility to BRAF-driven colorectal cancer. Cell Rep 21: 3833-3845, 2017

89. Durinikova E, Kozovska Z, Poturnajova M, Plava J, Cierna Z, Babelova A, Bohovic R, Schmidtova S, Tomas M, Kucerova L and Matuskova M: ALDH1 A3 upregulation and spontaneous metastasis formation is associated with acquired chemoresistance in colorectal cancer cells. BMC Cancer 18: 848, 2018.

90. Boland CR and Goel A: Microsatellite instability in colorectal cancer. Gastroenterology 138: 2073-2087.e3, 2010.

91. Mármol I, Sánchez-de-Diego C, Pradilla Dieste A, Cerrada E and Rodriguez Yoldi MJ: Colorectal carcinoma: A general overview and future perspectives in colorectal cancer. Int J Mol Sci 18: 197, 2017
92. Jung J, Kang Y, Lee YJ, Kim E, Ahn B, Lee E, Kim JY, Lee JH, Lee Y, Kim CH and Chae YS: Comparison of the mismatch repair system between primary and metastatic colorectal cancers using immunohistochemistry. J Pathol Transl Med 51: 129-136, 2017.

93. Chen W, Swanson BJ and Frankel WL: Molecular genetics of microsatellite-unstable colorectal cancer for pathologists. Diagn Pathol 12: 24, 2017.

94. Pino MS and Chung DC: The chromosomal instability pathway in colon cancer. Gastroenterology 138: 2059-2072, 2010

95. Thanki K, Nicholls ME, Gajjar A, Senagore AJ, Qiu S, Szabo C, Hellmich MR and Chao C: Consensus molecular subtypes of colorectal cancer and their clinical implications. Int Biol Biomed J 3: 105-111, 2017.

96. Fumagalli A, Drost J, Suijkerbuijk SJ, van Boxtel R, de Ligt J, Offerhaus GJ, Begthel H, Beerling E, Tan EH, Sansom OJ, et al: Genetic dissection of colorectal cancer progression by orthotopic transplantation of engineered cancer organoids. Proc Natl Acad Sci USA 114: E2357-E2364, 2017.

97. Zhao M, Mishra L and Deng CX: The role of TGF- $\beta$ /SMAD4 signaling in cancer. Int J Biol Sci 14: 111-123, 2018.

98. Boutin AT, Liao WT, Wang M, Hwang SS, Karpinets TV, Cheung $\mathrm{H}$, Chu GC, Jiang S, Hu J, Chang K, et al: Oncogenic KRAS drives invasion and maintains metastases in colorectal cancer. Genes Dev 31: 370-382, 2017.

99. Wenzel J, Rose K, Haghighi EB, Lamprecht C, Rauen G, Freihen V, Kesselring R, Boerries M and Hecht A: Loss of the nuclear Wnt pathway effector TCF7L2 promotes migration and invasion of human colorectal cancer cells. Oncogene 39: 3893-3909, 2020.

100. Major MB, Camp ND, Berndt JD, Yi X, Goldenberg SJ, HubbertC, Biechele TL, Gingras AC, Zheng N, Maccoss MJ, et al: Wilms tumor suppressor WTX negatively regulates WNT/beta-catenin signaling. Science 316: 1043-1046, 2007.

101. Steffen DJ, Amornphimoltham P, Valera JLC, Taylor S, Hunter T, Tamayo P and Gutkind JS: GNAS-PKA Oncosignaling Network in Colorectal Cancer. Pharmacology 31: lb527, 2017.

102. Lieu C and Kopetz S: The SRC family of protein tyrosine kinases: A new and promising target for colorectal cancer therapy. Clin Colorectal Cancer 9: 89-94, 2010.

103. Jin X, Zhai B, Fang T, Guo X and Xu L: FXR1 is elevated in colorectal cancer and acts as an oncogene. Tumor Biol 37: 2683-2690, 2016

104. Gumireddy K, Li A, Yan J, Setoyama T, Johannes GJ, Ørom UA, Tchou J, Liu Q, Zhang L, Speicher DW, et al: Identification of a long non-coding RNA-associated RNP complex regulating metastasis at the translational step. EMBO J 32: 2672-2684, 2013.

105. Xia P, Choi AH, Deng Z, Yang Y, Zhao J, Wang Y, Hardwidge PR and Zhu G: Cell membrane-anchored MUC4 promotes tumorigenicity in epithelial carcinomas. Oncotarget 8: 14147-14157, 2017.

106. De Robertis M, Arigoni M, Loiacono L, Riccardo F, Calogero RA, Feodorova Y, Tashkova D, Belovejdov V, Sarafian V, Cavallo F and Signori E: Novel insights into Notum and glypicans regulation in colorectal cancer. Oncotarget 6: 41237-41257, 2015.

107. Lui VW, Peyser ND, Ng PK, Hritz J, Zeng Y, Lu Y, Li H, Wang L, Gilbert BR, General IJ, et al: Frequent mutation of receptor protein tyrosine phosphatases provides a mechanism for STAT3 hyperactivation in head and neck cancer. Proc Natl Acad Sci USA 111: 1114-1119, 2014

108. Brabletz T, Jung A, Reu S, Porzner M, Hlubek F, Kunz-Schughart LA, Knuechel R and Kirchner T: Variable beta-catenin expression in colorectal cancers indicates tumor progression driven by the tumor environment. Proc Natl Acad Sci USA 98: 10356-10361, 2001

109. Fodde R, Smits R and Clevers H: APC, signal transduction and genetic instability in colorectal cancer. Nat Rev Cancer 1: 55-67, 2001.

110. Gregorieff A and Clevers H: Wnt signaling in the intestinal epithelium: From endoderm to cancer. Genes Dev 19: 877-890, 2005

111. Brabletz T, Jung A, Hermann K, Günther K, Hohenberger W and Kirchner T: Nuclear overexpression of the oncoprotein beta-catenin in colorectal cancer is localized predominantly at the invasion front. Pathol Res Pract 194: 701-704, 1998.

112. Le NH, Franken P and Fodde R: Tumour-stroma interactions in colorectal cancer: Converging on beta-catenin activation and cancer stemness. Br J Cancer 98: 1886-1893, 2008.

113. Teeuwssen $\mathrm{M}$ and Fodde R: Cell heterogeneity and phenotypic plasticity in metastasis formation: The case of colon cancer. Cancers (Basel) 11: 1368, 2019. 
114. Brocardo M and Henderson B: APC shuttling to the membrane nucleus and beyond. Trends Cell Boil 18: 587-596, 2008.

115. Sarli L, Bottarelli L, Bader G, Iusco D, Pizzi S, Costi R, D'Adda T, Bertolani M, Roncoroni L and Bordi C: Association between recurrence of sporadic colorectal cancer, high level of microsatellite instability, and loss of heterozygosity at chromosome 18q. Dis Colon Rectum 47: 1467-1482, 2004.

116. Munro AJ, Lain S and Lane DP: P53 abnormalities and outcomes in colorectal cancer: A systematic review. Br J Cancer 92: 434-444, 2005.

117. Prior IA, Lewis PD and Mattos C: A comprehensive survey of Ras mutations in cancer. Cancer Res 72: 2457-2467, 2012.

118. Makrodouli E, Oikonomou E, Koc M, Andera L, Sasazuki T, Shirasawa $S$ and Pintzas A: BRAF and RAS oncogenes regulate Rho GTPase pathways to mediate migration and invasion properties in human colon cancer cells: A comparative study. Mol Cancer 10: 118, 2011.

119. Lemieux E, Bergeron S, Durand V, Asselin C, Saucier C and Rivard N: Constitutively active MEK1 is sufficient to induce epithelial-to-mesenchymal transition in intestinal epithelial cells and to promote tumor invasionand metastasis. Int J Cancer 125 : 1575-1586, 2009.

120. Yamazaki D, Kurisu S and Takenawa T: Involvement of Rac and Rho signaling in cancer cell motility in 3D substrates. Oncogene 28: 1570-1583, 2009.

121. Sanz-Moreno V and Marshall CJ: The plasticity of cytoskeletal dynamics underlying neoplastic cell migration. Curr Opin Cell Biol 22: 690-696, 2010.

122. Koveitypour Z, Panahi F, Vakilian M, Peymani M, Seyed Forootan F, Nasr Esfahani MH and Ghaedi K: Signaling pathways involved in colorectal cancer progression. Cell Biosci 9: 97, 2019

123. Atreya CE, Sangale Z, Xu N, Matli MR, Tikishvili E, Welbourn W, Stone S, Shokat KM and Warren RS: PTEN expression is consistent in colorectal cancer primaries and metastases and associates with patient survival. Cancer Med 2: 496-506, 2013.

124. Day F, Muranyi A, Singh S, Shanmugam K, Williams D, Byrne D, Pham K, Palmieri M, Tie J, Grogan T, et al: A mutant BRAF V600E-specific immunohistochemical assay: Correlation with molecular mutation status and clinical outcome in colorectal cancer. Target Oncol 10: 99-109, 2015.

125. Yaeger R, Cercek A, O'Reilly EM, Reidy DL, Kemeny N, Wolinsky T, Capanu M, Gollub MJ, Rosen N, Berger MF, et al Pilot trial of combined BRAF and EGFR inhibition in BRAF-mutant metastatic colorectal cancer patients. Clin Cancer Res 21: 1313-1320, 2015

126. Wong CK, Lambert AW, Ozturk S, Papageorgis P, Lopez D, Shen N, Sen Z, Abdolmaleky HM, Győrffy B, Feng H and Thiagalingam S: Targeting RICTOR sensitizes SMAD4-negative colon cancer to irinotecan. Mol Cancer Res 18: 414-423, 2020.

127. Zou Z, Tao T, Li H and Zhu X: mTOR signaling pathway and mTOR inhibitors in cancer: Progress and challenges. Cell Biosci 10: 31, 2020.

128. Demkova L and Kucerova L: Role of the HGF/c-MET tyrosine kinase inhibitors in metastasic melanoma. Mol Cancer 17: 26, 2018.

129. Cui YM, Jiao HL, Ye YP, Chen CM, Wang JX, Tang N, Li TT, Lin J, Qi L, Wu P, et al: FOXC2 promotes colorectal cancer metastasis by directly targeting MET. Oncogene 34: 4379-4390, 2015.

130. Stein U, Walther W, Arlt F, Schwabe H, Smith J, Fichtner I, Birchmeier W and Schlag PM: MACC1, a newly identified key regulator of HGF-MET signaling, predicts colon cancer metastasis. Nat Med 15: 59-67, 2009.

131. Pichorner A, Sack U, Kobelt D, Kelch I, Arlt F, Smith J, Walther W, Schlag PM and Stein U: In vivo imaging of colorectal cancer growth and metastasis by targeting MACC1 with shRNA in xenografted mice. Clin Exp Metastasis 29: 573-583, 2012

132. Juneja M, Kobelt D, Walther W, Voss C, Smith J, Specker E, Neuenschwander M, Gohlke B, Dahlmann M, Radetzki S, et al: Statin and rottlerin small-molecule inhibitors restrict colon cancer progression and metastasis via MACC1. PLoS Biol 15: e2000784, 2017

133. Glebov OK, Rodriguez LM, Nakahara K, Jenkins J, Cliatt J, Humbyrd CJ, DeNobile J, Soballe P, Simon R, Wright G, et al: Distinguishing right from left colon by the pattern of gene expression. Cancer Epidemiol Biomark Prev 12: 755-762, 2003.

134. Baran B, Mert Ozupek N, Yerli Tetik N, Acar E, Bekcioglu O and Baskin Y: Difference between left-sided and right-sided colorectal cancer: A focused review of literature. Gastroenterol Res 11: 264-273, 2018
135. Lee MS, Menter DG and Kopetz S: Right versus left colon cancer biology: Integrating the consensus molecular subtypes. J Natl Compr Canc Netw 15: 411-419, 2017.

136. Weinberg BA: Anti-EGFR therapy in right-sided metastatic colorectal cancer: Right or wrong? J Natl Compr Canc Netw 16: 1547-1548, 2018.

137. Loree JM, Pereira AAL, Lam M, Willauer AN, Raghav K, Dasari A, Morris VK, Advani S, Menter DG, Eng C, et al: Classifying colorectal cancer by tumor location rather than sidedness highlights a continuum in mutation profiles and consensus molecular subtypes. Clin Cancer Res 24: 1062-1072, 2018.

138. Hugen N, Brown G, Glynne-Jones R, de Wilt JH and Nagtegaal ID: Advances in the care of patients with mucinous colorectal cancer. Nat Rev Clin Oncol 13: 361-369, 2016.

139. Esterházy D, Canesso MC, Mesin L, Muller PA, de Castro TB, Lockhart A, ElJalby M, Faria AM and Mucida D: Compartmentalized gut lymph node drainage dictates adaptive immune responses. Nature 569: 126-130, 2019.

140. Piskounova E, Agathocleous M, Murphy MM, Hu Z, Huddlestun SE, Zhao Z, Leitch AM, Johnson TM, DeBerardinis RJ and Morrison SJ: Oxidative stress inhibits distant metastasis by human melanoma cells. Nature 527: 186-191, 2015.

141. Llosa NJ, Cruise M, Tam A, Wicks EC, Hechenbleikner EM, Taube JM, Blosser RL, Fan H, Wang H, Luber BS, et al: The vigorous immune microenvironment of microsatellite instable colon cancer is balanced by multiple counter-inhibitory checkpoints. Cancer Discov 5: 43-51, 2015.

142. Deschoolmeester V, Baay M, Van Marck E, Weyler J, Vermeulen P, Lardon F and Vermorken JB: Tumor infiltrating lymphocytes: An intriguing player in the survival of colorectal cancer patients. BMC Immunol 11: 19, 2010.

143. Salama P, Phillips M, Grieu F, Morris M, Zeps N, Joseph D, Platell $\mathrm{C}$ and Iacopetta B: Tumor-infiltrating FOXP $3^{+} \mathrm{T}$ regulatory cells show strong prognostic significance in colorectal cancer. J Clin Oncol 27: 186-192, 2009.

144. Schwitalle Y, Kloor M, Eiermann S, Linnebacher M, Kienle P, Knaebel HP, Tariverdian M, Benner A and von Knebel Doeberitz M: Immune response against frameshift-induced neopeptides in HNPCC patients and healthy HNPCC mutation carriers. Gastroenterology 134: 988-997, 2008.

145. Han Y, Liu D and Li L: PD-1/PD-L1 pathway: Current researches in cancer. Am J Cancer Res 10: 727-742, 2020

146. Kreidieh M, Mukherji D, Temraz S and Shamseddine A: Expanding the scope of immunotherapy in colorectal cancer: Current clinical approaches and future directions. Biomed Res Int 2020: 9037217, 2020.

147. Kroemer G, Galluzzi L, Zitvogel L and Fridman WH: Colorectal cancer: The first neoplasia found to be under immunosurveillance and the last one to respond to immunotherapy? Oncoimmunology 4: e1058597, 2015.

148. Le DT, Uram JN, Wang H, Bartlett BR, Kemberling H, Eyring $\mathrm{AD}$, Skora $\mathrm{AD}$, Luber BS, Azad NS, Laheru D, et al: PD-1 blockade in tumors with mismatch-repair DEfiCiency. N Engl J Med 372: 2509-2520, 2015.

149. Mlecnik B, Bindea G, Kirilovsky A, Angell HK, Obenauf AC, Tosolini M, Church SE, Maby P, Vasaturo A, Angelova M, et al: The tumor microenvironment and Immunoscore are critical determinants of dissemination to distant metastasis. Sci Trans Med 8: 327ra26, 2016.

150. Mlecnik B, Van den Eynde M, Bindea G, Church SE, Vasaturo A, Fredriksen T, Lafontaine L, Haicheur N, Marliot F, Debetancourt D, et al: Comprehensive intrametastatic immune quantification and major impact of immunoscore on survival. J Natl Cancer Inst 110: 97-108, 2018.

151. Girardin A, McCall J, Black MA, Edwards F, Phillips V, Taylor ES, Reeve AE and Kemp RA: Inflammatory and regulatory $\mathrm{T}$ cells contribute to a unique immune microenvironment in tumor tissue of colorectal cancer patients. Int J Cancer 132: 1842-1850, 2013.

152. Pedrosa L, Esposito F, Thomson TM and Mauriel J: The tumor microenvironment in colorectal cancer therapy. Cancers (Basel) 11: 1172, 2019.

153. Kalluri R and Zeisberg M: Fibroblasts in cancer. Nat Rev Cancer 6: 392-401, 2006

154. Malanchi I, Santamaria-Martínez A, Susanto E, Peng H, Lehr HA, Delaloye JF and Huelsken J: Interactions between cancer stem cells and their niche govern metastatic colonization. Nature 481: 85-89, 2011. 
155. Calon A, Espinet E, Palomo-Ponce S, Tauriello DV, Iglesias M, Céspedes MV, Sevillano M, Nadal C, Jung P, Zhang XH, et al: Dependency of colorectal cancer on a TGF- $\beta$-driven program in stromal cells for metastasis initiation. Cancer Cell 22: 571-584, 2012.

156. Brown RE, Short SP and Williams CS: Colorectal cancer and metabolism. Curr Colorectal Cancer Rep 14: 226-241, 2018.

157. Gureev AP, Shaforostova EA and Popov VN: Regulation of mitochondrial biogenesis as a way for active longevity: Interaction between the Nrf 2 and $\mathrm{PGC}-1 \alpha$ signaling pathways. Front Genet 10: 435, 2019

158. Chang CH, Qiu J, O'Sullivan D, Buck MD, Noguchi T, Curtis JD, Chen Q, Gindin M, Gubin MM, van der Windt GJ, et al: Metabolic competition in the tumor microenvironment is a driver of cancer progression. Cell 162: 1229-1241, 2015.

159. Vyas M, Patel N, Nagarajan A, Wajapeyee N, Jain D and Zhan X: Hypoxia induced HIF-l $\alpha$ expression promotes angiogenesis, tumor budding cell survival and cell proliferation arrest in high-grade tumor budding colorectal carcinomas. Int J Clin Exp Patho 9: 13047-13055, 2016.

160. Ancey PB, Contat C and Meylan E: Glucose transporters in cancer-from tumor cells to the tumor microenvironment. FEBS J 285: 2926-2943, 2018.

161. Ritterson Lew C, Guin S and Theodorescu D: Targeting glycogen metabolism in bladder cancer. Nat Rev Urol 12: 383-391, 2015.

162. Kuo CC, Ling HH, Chiang MC, Chung CH, Lee WY, Chu CY, Wu YC, Chen CH, Lai YW, Tsai IL, et al: Metastatic colorectal cancerrewrites metabolic program through a Glut3-YAP-dependent signaling circuit. Theranostics 9: 2526-2540, 2019.

163. DeBerardinis RJ: Is cancer a disease of abnormal cellular metabolism? New angles on an old idea. Genet Med 10: 767-777, 2008.

164. Weber GF: Metabolism in cancer metastasis. Int Jour Cancer 138 2061-2066, 2016.

165. Corté H, Manceau G, Blons H and Laurent-Puig P: MicroRNA and colorectal cancer. Dig liver dis 44: 195-200, 2012.

166. Bu P, Chen KY, Xiang K, Johnson C, Crown SB, Rakhilin N, Ai Y, Wang L, Xi R, Astapova I, et al: Aldolase B-mediated fructose metabolism drives metabolic reprogramming of colon cancer liver metastasis. Cell Metab 27: 1249-1262.e4, 2018

167. Wu Z, Wei D, Gao W, Xu Y, Hu Z, Ma Z, Gao C, Zhu X and Li Q: TPO-induced metabolic reprogramming drives liver metastasis of colorectal cancer $\mathrm{CD} 110^{+}$tumor-initiating cells Cell Stem Cells 17: 47-59, 2015.

168. Calin GA, Sevignani C, Dumitru CD, Hyslop T, Noch E, Yendamuri S, Shimizu M, Rattan S, Bullrich F, Negrini M and Croce CM: Human microRNA genes are frequently located at fragile sites and genomic regions involved in cancers. Proc Nat Acad Sci USA 101: 2999-3004, 2004

169. Cellura D, Pickard K, Quaratino S, Parker H, Strefford JC, Thomas GJ, Mitter R, Mirnezami AH and Peake NJ: miR-19-mediated inhibition of transglutaminase-2 leads to enhanced invasion and metastasis in colorectal cancer. Mol Cancer Res 13: 1095-1105, 2015.

170. Lam CS, Ng L, Chow AK, Wan TM, Yau S, Cheng NS, Wong SK, Man JH, Lo OS, Foo DC, et al: Identification of microRNA $885-5 \mathrm{p}$ as a novel regulator of tumor metastasis by targeting CPEB2 in colorectal cancer. Oncotarget 8: 26858-26870, 2017.

171. Shibuya H, Iinuma H, Shimada R, Horiuchi A and Watanabe T: Clinicopathological and prognostic value of microRNA-21 and microRNA-155 in colorectal cancer. Oncology 79: 313-320, 2010.

172. Asangani IA, Rasheed SA, Nikolova DA, Leupold JH, Colburn NH, Post S and Allgayer H: MicroRNA-21 (miR-21) post-transcriptionally downregulates tumor suppressor Pded4 and stimulates invasion, intravasation and metastasis in colorectal cancer. Oncogene 27: 2128-2136, 2008.

173. Loo JM, Scherl A, Nguyen A, Man FY, Weinberg E, Zeng Z, Saltz L, Paty PB and Tavazoie SF: Extracellular metabolic energetics can promote cancer progression. Cell 160: 393-406, 2015.

174. Chi Y and Zhou D: MicroRNAs in colorectal carcinoma-from pathogenesis to therapy. J Exp Clin Cancer Res 35: 43, 2016.
175. Heublein S, Albertsmeier M, Pfeifer D, Loehrs L, Bazhin AV, Kirchner T, Werner J, Neumann J and Angele MK: Association of differential miRNA expression with hepatic vs. peritoneal metastatic spread in colorectal cancer. BMC Cancer 18: 201, 2018.

176. Siemens H, Neumann J, Jackstadt R, Mansmann U, Horst D, Kirchner T and Hermeking H: Detection of miR-34a promoter methylation in combination with elevated expression of c-Met and $\beta$-catenin predicts distant metastasis of colon cancer. Clin Cancer Res 19: 710-720, 2013.

177. Ma YS, Lv ZW, Yu F, Chang ZY, Cong XL, Zhong XM, Lu GX, Zhu J and Fu D: MicroRNA-302a/d inhibits the self-renewal capability and cell cycle entry of liver cancer stem cells by targeting the E2F7/AKT axis. J Exp Clin Cancer Res 37: 252, 2018.

178. Shi L, Jackstadt R, Siemens H,LiH, KirchnerT and Hermeking H: p53-induced miR-15a/16-1 and AP4 form a double-negative feedback loop to regulate epithelial-mesenchymal transition and metastasis in colorectal cancer. Cancer Res 74: 532-542, 2014.

179. Yan TT, Ren LL, Shen CQ, Wang ZH, Yu YN, Liang Q, Tang JY, Chen YX, Sun DF, Zgodzinski W, et al: miR-508 defines the stem-like/mesenchymal subtype in colorectal cancer. Cancer Res 78: 1751-1765, 2018.

180. Hur K, Toiyama Y, Takahashi M,BalaguerF, Nagasaka T, Koike J, Hemmi H, Koi M, Boland CR and Goel A: MicroRNA-200c modulates epithelial-to-mesenchymal transition (EMT) in human colorectal cancer metastasis. Gut 62: 1315-1326, 2013.

181. Sun Z,Zhang Z, Liu Z, Qiu B, Liu K and Dong G: MicroRNA-335 inhibits invasion and metastasis of colorectal cancer by targeting ZEB2. Med Oncol 31: 982, 2014.

182. Geng L, Chaudhuri A, Talmon G, Wisecarver JL, Are C, Brattain M and Wang J: MicroRNA-192 suppresses liver metastasis of colon cancer. Oncogene 33: 5332-5340, 2014.

183. Hahn S, Jackstadt R, Siemens H, Hünten S and Hermeking H: SNAIL and miR-34a feed-forward regulation of ZNF281/ZBP99 promotes epithelial-mesenchymal transition. EMBO J 32: 3079-3095, 2013.

184. Miranda E, Destro A, Malesci A, Balladore E, Bianchi P, Baryshnikova E, Franchi G, Morenghi E, Laghi L, Gennari L and Roncalli M: Genetic and epigenetic changes in primary metastatic and nonmetastatic colorectal cancer. Br J Cancer 95: 1101-1107, 2006.

185. Li Z, Chen Y, Ren WU, Hu S, Tan Z, Wang Y, Chen Y, Zhang J, $\mathrm{Wu}$ J, Li T, et al: Transcriptome alterations in liver metastases of colorectal cancer after acquired resistance to cetuximab. Cancer Genom Proteom 16: 207-219, 2019.

186. Markowitz SD and Bertagnolli MM: Molecular origins of cancer: Molecular basis of colorectal cancer. N Engl J Med 361: 2449-2460, 2009

187. Garinis GA, Menounos PG, Spanakis NE, Papadopoulos K, Karavitis G, Parassi I, Christeli E, Patrinos GP, Manolis EN and Peros G: Hypermethylation-associated transcriptional silencing of E-cadherin in primary sporadic colorectal carcinomas. J Pathol 198: 442-449, 2002.

188. Ryall JG, Cliff T, Dalton S and Sartorelli V: Metabolic reprogramming of stem cell epigenetics. Cell Stem Cell 17: 651-662, 2015.

189. Kim JA and Yeom YI: Metabolic signaling to epigenetic alterations in cancer. Biomol Ther (Seoul) 26: 69-80, 2018.

190. Zee BM, Levin RS, Xu B, LeRoy G, Wingreen NS and Garcia BA: In vivo residue-specific histone methylation dynamics. J Biol Chem 285: 3341-3350, 2010.

191. Tse JWT, Jenkins LJ, Chionh F and Mariadason JM: Aberrant DNA methylation in colorectal cancer: What should we target? Trends Cancer 3: 698-712, 2017.

192.Zentner GE and Henikoff S: Regulation of nucleosome dynamics by histone modifications. Nat Struct Mol Biol 20: 259-266, 2013.

This work is licensed under a Creative Commons Attribution-NonCommercial-NoDerivatives 4.0 International (CC BY-NC-ND 4.0) License. 